\title{
LA CONSTITUCIÓN Y LA ESFERA PÚBLICA: ENTRE DIFERENCIACIÓN SISTÉMICA, INCLUSIÓN Y RECONOCIMIENTO
}

\author{
Marcelo Neves \\ Universidad de Brasilia
}

\begin{abstract}
RESUMEN. Tras algunas aclaraciones iniciales, el trabajo arranca con una presentación del concepto de Constitución y del de esfera pública pluralista. A partir de ahí analiza los conceptos de inclusión (como posición de la persona en relación a los sistemas funcionales) y de reconocimiento (como problema de doble contingencia en la interacción cotidiana). Y concluye ocupándose de los límites de la esfera pública y de la posibilidad de que puedan ser superados en el ámbito de la estructura de una sociedad mundial.
\end{abstract}

Palabras clave: Constitución, esfera pública pluralista, inclusión, reconocimiento.

\section{Constitution and Public Sphere: Systemic differentiation, inclusion and recognition}

ABSTRACT. After some initial explanations, the author introduces the concept of Constitution and that of a plural public sphere. Drawing from them, an analyses of the concepts of inclusion (in terms of where the person stands in functional systems) and recognition (in terms of a problem of double contingency in daily interaction) is undertaken. Finally, as a conclusion, the paper reflects on the limits of the public sphere and on the possibility to overcome them at the level of a worldwide society structure.

Keywords: Constitution, plural public sphere, inclusion, recognition.

* Fecha de recepción: 5 de noviembre de 2013. Fecha de aceptación: 12 de mayo de 2014. 
1.

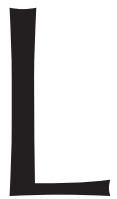

a Constitución viene siendo considerada, de manera reciente, como una metáfora del discurso o retórica política y jurídica. En tal sentido, y de forma paradójica, correspondería a un mero instrumento de la semántica de la sociedad sin una correspondencia específica en la estructura de la misma, y a la que en tales condiciones sería posible recurrir discursivamente en los contextos más diversos. Este enfoque característico del deconstructivismo y de los modelos posmodernos me parece poco fructífero para el tratamiento de los problemas jurídicopolíticos de la sociedad moderna (mundial), en la cual la semántica constitucionalista se relaciona con los cambios en la estructura social.

Sin duda, el término «Constitución» es efectivamente una de las metáforas de la semántica social contemporánea (y, en ese sentido amplio, ¿qué termino finalmente no lo es?), pero esto no necesariamente trae consigo un vacío de significado, es decir, su transformación en un «significante fluctuante», «valor simbólico cero» ${ }^{1} \mathrm{o}$ «significante vacío» ${ }^{2}$. El constitucionalismo, en cuanto construcción de la sociedad moderna, envuelve ciertos contornos de sentido que impiden una desconexión de carácter absoluto entre la semántica constitucional y las transformaciones estructurales. Tales contornos de sentido posibilitan relacionar las crisis que ocurren a nivel semántico con problemas emergentes en el plano de las estructuras. De hecho, existen tensiones entre la semántica desarrollada a nivel de autodescripción o reflexión de la sociedad, y el plano estructural de la delimitación selectiva de las operaciones posibles, pero es evidente que los cambios estructurales provocan cambios en el aparato semántico y viceversa ${ }^{3}$. Cabe observar que no sólo las innovaciones semánticas se relacionan con transformaciones estructurales ${ }^{4}$, sino también que la obsolescencia de las semánticas específicas puede estar asociada con el agotamiento de las estructuras respectivas ${ }^{5}$.

Observaciones semejantes deben ser hechas respecto de la «esfera pública» («Öffentlichkeit», «space public») en cuanto dimensión de la sociedad contemporánea. Tampoco nos encontramos aquí frente a una mera metáfora, desvinculada de ciertas implicaciones estructurales ${ }^{6}$; es imposible recurrir indiscriminadamente a dicho concepto en contextos sociales diversos, convirtiéndolo —en sentido wittgensteinianoen un componente de «juegos del lenguaje», seductores y «extraños» a la respectiva

1 LÉVI-STRAuSs, 1973: XLIX y ss., nota 1 (trad. bras. 1974: 35, nota 37).

2 LACLAU, 1994.

3 Cfr. LuHManN, 1980: 17, 22 y 34.

4 Cfr. LuHMANN, 1990a: 177, citando SKINNER, 1989.

5 «Si el nivel de complejidad social se modifica, la semántica orientadora de la vivencia y la acción precisa adecuarse, porque de lo contrario pierde su conexión con la realidad» (LUHMANN, 1980: 22).

6 En este contexto, denomino como «mera metáfora» aquella que carece de función o valor descriptivo, debido a que las posibilidades de su despliegue son limitadas, arbitrarias o aleatorias. Asimismo, podría ser denominada como «metáfora arbitraria». Sobre la distinción entre metáfora que deja abiertos «elementos fundamentales» de la descripción, y el concepto que se asocia a la descripción «precisa», vid. MÖLLERS, 2005: 286 y ss. En un contexto diferente y con otros presupuestos, BLUMENBERG (1998: 10 y 13) se refiere a la «metáfora absoluta» de la siguiente manera: «La verificación y el análisis de su función asertiva no separable de "conceptos" constituirían "una pieza fundamental de la historia de los conceptos (en este sentido amplio)" y estarían en una relación de "prestación" con la "historia de los conceptos (en el sentido terminológico escrito)"». 
«forma de vida» ${ }^{7}$, es decir, sin soporte estructural. Sin negar la existencia ni la relevancia de los juegos del lenguaje metafóricos, me parece, sin embargo, que ellos pueden tener una relación inadecuada con los contextos estructurales, en la medida en que no sirven como solución oportuna de los problemas sociales que emergen de las deficiencias de las estructuras. Imaginemos, por ejemplo, describir mediante el concepto de esfera pública las luchas tribales en el ámbito de los «failed states» de África ${ }^{8}$. Indiscutiblemente, sería un despropósito. De la misma manera, considero inadecuado hacer referencia a la distinción entre «privado» y «público» en los términos de la diferencia existente en la Grecia antigua, entre oikos u oikia y pólis, asociando la última de estas expresiones a la esfera pública moderna. «Público» en el mundo helénico, más precisamente en la Ciudad-Estado griega, está referido a la pólis como espacio excluyente de relación de los señores de los «oikoi» o de las «oikias», a diferencia de las aldeas que sólo constituían agregados de éstas ${ }^{9}$. Los oikos, a su vez, eran el espacio social de carácter doméstico (privado) de pleno arbitrio del respectivo señor sobre su familia, sus esclavos y siervos ${ }^{10}$. Así como el oikos griego (gran espacio doméstico de las relaciones «familiares» o de la «gran» familia, fundado en el poder arbitrario del señor) no corresponde ni al espacio doméstico de la «pequeña» familia moderna (lo «privado» en el sentido familiar), ni al espacio del mercado mundial (lo «privado» en el sentido económico), la pólis excluyente (dimensión de lo público en sentido griego) no debe ser confundida con el sistema político de la sociedad moderna, mucho menos con la esfera pública incluyente y pluralista en el sentido contemporáneo ${ }^{11}$.

Hechas estas aclaraciones preliminares, haré una breve exposición del concepto y de la función de la Constitución, como conquista y construcción de la sociedad moderna, conectando la semántica del constitucionalismo con las estructuras constitucionales (2.). Enseguida, intentaré delimitar el concepto de esfera pública pluralista, como arena del disenso estructural frente a los procedimientos de producción y concretización normativo-jurídica y en la toma o ejecución de decisiones políticas (3.). Basado en esos presupuestos conceptuales, discutiré los problemas recientes de la relación entre los procedimientos constitucionales del Estado democrático de derecho y la esfera pública, enlazándolo con las dificultades provenientes de nuevas tendencias a la exclusión y a la negación del «reconocimiento» en el contexto de una sociedad global; en tal sentido, serán abordados los conceptos de «inclusión» como posición de la persona en relación a los sistemas funcionales, y de «reconocimiento» como problema de doble contingencia en la interacción cotidiana. Partiendo de la comprensión de que tanto la inclusión como el reconocimiento son presupuestos de una esfera pública pluralista, en cuanto arena del disenso localizado en el entorno de los procedimientos constitucionales del Estado democrático de derecho (4.). Por último, en la conclusión trataré

7 «Y representar un lenguaje significa representarse una forma de vida» [WITTGENSTEIN, 1997 (19451949): 246, $\mathbb{1} 19$ (trad. bras. 1979: 15)]. «Lo aceptado, lo dado — podría decirse—, son formas de vida» [ibid., 572 (trad. bras.: 218)].

8 Sobre failed states, vid. THÜRER, 1996.

9 Cfr. LuHMann, 2000a: 7.

10 Los oikos (los oikoi) era(n) más amplios que la(s) oikia(s), ya que incluía(n) también las cosas que lo(s) respectivo(s) señor(es) poseía(n) fuera de esto(s) (cfr. MACDOWELL, 1989: 10).

11 La tendencia a relacionar y confundir la diferencia griega entre pólis y oikos con la distinción simplificada entre público y privado en la sociedad moderna se asocia a la obra de Hannah ARENDT [cfr. 1989 (1958): 28 y ss.]. 
acerca de los límites de la esfera pública pluralista o de la posibilidad de su superación en el ámbito de la estructura de una sociedad mundial, cuya autocomprensión es cada vez más relevante en la semántica de la globalización (5.).

2.

La Constitución es una conquista, construcción o invención de la sociedad moderna. En tal sentido, no cabe confundirla con la politéia griega, correspondiente a la estructura orgánica de la pólis. El término «politeia» fue traducido, de manera aproximada, por el vocablo inglés «government» y utilizado hasta finales del siglo XVIII ${ }^{12}$, y resulta - cuando menos - extraño que en pleno periodo revolucionario fuese vertida en el término «constitution», cuando las transformaciones estructurales hacían precisamente tal traducción totalmente inadecuada. La semántica del constitucionalismo se refería a una «adquisición evolutiva de la sociedad moderna» ${ }^{13}$, incompatible con la concepción de la politeia en la antigua Grecia, que aludía a un modelo jerárquico y excluyente de indiferenciación entre política y derecho.

De igual forma, no corresponde confundir a la Constitución con las leyes fundamentales o pactos de poder de la transición a la modernidad. Dichos pactos eran particulares en la dimensión social, o en el ámbito personal de validez, refiriéndose a ciertos acuerdos entre el monarca y la nobleza o parte de la burguesía. Ya en la denominada dimensión material o ámbito material de validez, dichos pactos eran de carácter puntual, abarcando temas específicos correspondientes a la política y al derecho estatal. Asimismo, tales pactos tenían un carácter «fáctico», no en el sentido de ausencia de normas jurídicas, sino más bien en cuanto no implicaban una diferenciación operativa entre política y derecho, constituyendo una simple expresión jurídica de las relaciones reales de dominación. En tal sentido, dichos pactos eran, en el ámbito de la validez o en la dimensión temporal, meros «modificadores del poder», toda vez que expresaban cambios ocurridos a nivel de la estructura de dominación ${ }^{14}$. Por el contrario, las Constituciones modernas tienen pretensión de ser universalistas en la dimensión social, o en el ámbito personal de validez, refiriéndose, de forma inclusiva, a todos los miembros de la respectiva organización jurídico-política atribuyéndoles derechos fundamentales. Asimismo, las Constituciones modernas son exhaustivas en la dimensión material de validez. Se refieren a las diversas ramas del derecho y a diversos procesos de toma de decisiones políticas. Son normativas, no solamente porque se componen de normas jurídicas, sino también, y de forma más específica, porque apuntan a la diferenciación funcional entre derecho y política, implicando la vinculación jurídica del poder, posibilitando su límite y control por medio del derecho. Finalmente, es pertinente destacar que las Constituciones en sentido moderno son constituyentes de poder en

12 STOURZH, 1975: 99 y ss., o 1989: 3 y ss.; MohnHaupt, 1995: 8.

13 Luhmann, 1990a.

14 Relaciono, en este contexto, los conceptos sociológicos o teórico-sociales luhmannianos de dimensión social, material y temporal [LUHMANN, 1987b (1972), S. 94 ff.], con los conceptos jurídicos de ámbitos personal, material y temporal de validez (KELSEN, 1960, S. 12 ff. u. 291 y ss.); sin desconocer que los presupuestos e implicaciones de las respectivas categorías son diversos, me parece posible constatar una cierta analogía entre ambos modelos conceptuales. 
la esfera de validez o dimensión temporal, en la medida en que instituyen una nueva estructura política, renovando la fundamentación normativa de la misma, positivada jurídicamente ${ }^{15}$.

Hay que señalar que no se trata aquí de un concepto histórico-universal de Constitución, ya sea de carácter normativo-jurídico ${ }^{16}$, sociológico ${ }^{17}$, o cultural ${ }^{18}$, en el sentido de que todo Estado u orden jurídico estuvo siempre dotado de una Constitución. Por el contrario, se trata de observar que el concepto de Constitución, en sentido moderno, está relacionado con las transformaciones estructurales que llevaron a la diferenciación funcional de la sociedad, y que lo hacen inconcebible en una formación social jerárquica de carácter pre-moderno. En las sociedades pre-modernas, la amalgama compuesta por la estructura política de dominación, reproducida en base a la diferencia entre poder inferior y poder superior ${ }^{19}$; y la semántica moral-religiosa construida sobre la distinción (moral) entre el bien y el $\mathrm{mal}^{20}$, indisociable a su vez de la diferencia (religiosa) entre trascendente e inmanente, prevalecía sobre todas las otras esferas de comunicación, que permanecían, de tal forma, determinadas heterónomamente. La semántica del bien apuntaba especialmente a la parte superior de la dominación social (política), residiendo en la «nobleza» o grupo funcionalmente equivalente. Por su parte, la semántica del mal estaba referida, de forma específica, a la parte inferior de la estructura de dominación, expresándose en la «plebe» o su equivalente funcional. Los «de abajo» sólo practicarían el bien en cuanto actuasen en conformidad con los modelos de comportamiento que les fuesen determinados por los «de arriba». Por su parte, éstos sólo practicarían el mal si actuasen conforme a los patrones de aquéllos ubicados en la parte inferior de la pirámide. Las demás esferas y códigos de comunicación estaban subordinadas a aquel andamiaje supremo, compuesto por la dominación política y la moral religiosamente determinada. El arte, la ciencia, el derecho y la economía estaban subordinados semánticamente a la diferencia entre el bien y el mal, como también orientados por los criterios de poder superior o inferior. Así las cosas, la diferencia entre lícito e ilícito (derecho) no se distinguía de la diferencia entre el bien y el mal, por el contrario, se confundía con ésta; su lado positivo se encontraba asociado con la parte superior de la dominación, y su lado negativo, con la inferior. Lo mismo ocurría con las diferencias «tener/no tener» (economía), «verdadero/falso» (ciencia), y «bello/ feo» (arte). El modelo jerárquico descrito resultaba incompatible con la Constitución en sentido moderno, que presupone la diferenciación funcional de la sociedad.

La diferenciación funcional frente a la amalgama pre-moderna formada por la política y la moral religiosa en la cúspide de la pirámide social ocurre inicialmente en el ámbito de la economía (la eficiencia lucrativa se distingue del bien y de lo políticamente dominante), la ciencia (la verdad como independiente de la moral religiosa y del poder) y del arte (lo «bello» o lo apropiado en sentido estético se vuelve autónomo respecto de la bondad moral con fundamento religioso). Se trata de procesos sociales

15 Respecto de las diferencias existente entre los conceptos de: leyes fundamentales o pactos de poder, y Constituciones en sentido moderno, vid. GRIMM, 1987: 48 y ss.; 1989, columnas 633 y ss.; 1995 : 100 y ss.

16 KeLSEN, 1960: 228-230; 1946: 124 y ss.; 1925: 251-253.

17 LASSALLE, 1987 (1862): 130; ENGELS, 1988 (1844): 572 y ss.; WEBER, 1985 (1922): 27.

18 Heller, 1934: 249 y ss.; SMEND, 1968: 136 y ss. y 189-191.

19 LuHManN, 1986, S. 199.

20 LuHManN, 1997: 939 y ss. y 1036. 
de carácter traumático, con consecuencias destructivas para el entorno biológico o psíquico de los sistemas sociales, en otras palabras, para el «cuerpo» y el «alma». Para ilustrar este punto, basta pensar en Galileo GALILEI, en el contexto del sistema de la ciencia (no nos olvidemos, sin embargo, en un campo diferente, de Romeo y Julieta, alegoría trágica de la pretensión moderna de autonomía del amor en relación con la política y la familia, pretensión que sólo se verá realizada mucho más tarde, impulsada también por la literatura novelesca ${ }^{21}$. Evidentemente, esos procesos de lucha por la autonomía de las diferentes esferas sociales, en el inicio de la era moderna, aún no implican una autonomía operativa del derecho en relación con el poder en cuanto dominación. El proceso moderno de diferenciación entre política y derecho sólo tendrá inicio al interior del constitucionalismo revolucionario de fines del siglo XVIII. Si bien los pactos de poder o leyes fundamentales en Inglaterra (Magna Carta, Habeas Corpus, Bill of Rights) apuntaban a un desarrollo funcionalmente equivalente al que condujo a las Constituciones revolucionarias en los Estados Unidos, y en Francia; no eran, aisladamente, expresiones semánticas del constitucionalismo, sino elementos de un proceso evolutivo de diferenciación entre derecho y política, que acabó en un constitucionalismo atípico en los siglos XIX y XX.

La Constitución, en sentido moderno, se relaciona con las transformaciones estructurales que sentaron las bases para el surgimiento de la sociedad burguesa. El aumento de la complejidad social llevó a la formación social diferenciada jerárquicamente de la pre-modernidad, a un punto muerto, y trajo consigo la emergencia de una creciente autonomía de las esferas de comunicación, en términos de sistemas funcionalmente diferenciados en la sociedad moderna. No se trata sólo de una separación entre ley, poder y saber ${ }^{22}$, ni de una simple emancipación religiosa y económica de la persona ${ }^{23}$, sino de un amplio proceso de diferenciación sistémico-funcional. Es dentro de este proceso donde surge la diferenciación entre política y derecho.

La idea de un poder político supremo, por encima del derecho, eje de la noción absolutista de la soberanía, pierde su significado, cediendo frente a la presión proveniente de los movimientos por la diferenciación del derecho en relación a la política. A su vez, dicho desarrollo no tiene un carácter lineal: implicó reacciones que sólo se realizaron de forma plena en partes muy restrictas del globo terrestre; y se encuentra relacionado con el surgimiento de la Constitución como una construcción social de la modernidad. La Constitución es el mecanismo que posibilita la diferenciación entre política y derecho en el ámbito de los Estados; no obstante, se trata de un mecanismo cuyo desarrollo depende de presupuestos sociales tan vastos, que sin un cierto contexto social de diferenciación funcional e inclusión social, no hay espacio para la Constitución como mecanismo de autonomía recíproca entre derecho y política. Sin la diferenciación funcional de las diversas esferas sociales, y sin la distinción clara y radical entre sociedad e individuo en cuanto persona, se vuelve imposible concebir a los derechos fundamentales como una respuesta del sistema jurídico frente a los mencionados procesos de diferenciación ${ }^{24}$. De la misma manera, sin autonomía de la polí-

${ }^{21}$ Cfr. Luhmann, 1990c (1982): 11 y ss.; 1997: 731.

22 LEFORT, 1981: 64

23 MARX, 1988 (1844): 369.

24 LuHMANN, 1965. 
tica en relación a los valores particulares de grupos familiares, étnicos y religiosos, y a los intereses económicos concretos, no se puede construir la democracia como apoyo generalizado que posibilita la clausura operativa del sistema político.

La Constitución, al mismo tiempo que posibilita la diferenciación entre sistema político y sistema jurídico, actúa como acoplamiento estructural entre ambos ${ }^{25}$. Pero, ¿qué significa esto? Esto quiere decir que los mecanismos de dos sistemas autónomos se influyen y afectan recíprocamente, de forma duradera y permanente, sin que ninguno de esos sistemas pierda su respectiva autonomía. Los acoplamientos estructurales son filtros que excluyen ciertas influencias y facilitan otras. Hay afectaciones recíprocas, vinculadas a la relación simultánea de independencia y dependencia entre los sistemas que se encuentran acoplados estructuralmente. No se trata de un mero acoplamiento operativo, momentáneo, sino de interpenetraciones e interferencias de carácter continuo. Las estructuras de un sistema pasan a ser, mediante los acoplamientos estructurales, relevantes e indispensables para la reproducción de las estructuras del otro sistema y viceversa. En tal sentido, funcionan como acoplamientos de este tipo el lenguaje en la relación entre consciencia y sociedad; los contratos y la propiedad en la relación entre derecho y economía; la tributación en la relación entre política y economía; las asesorías de especialistas («experts») en la relación entre política y ciencia; la universidad en la relación existente entre educación y ciencia; los títulos y diplomas en la relación entre economía y educación; las galerías de arte en la relación entre economía y arte ${ }^{26}$, etc. Entonces cabe preguntarse, ¿ cómo funciona la Constitución en cuanto acoplamiento estructural entre política y derecho? En cuanto acoplamiento estructural entre política y derecho, la Constitución, por un lado, convierte al código binario «lícito/ilícito» en relevante para el sistema político; esto implica que las exigencias del Estado de derecho y de los derechos fundamentales pasan a construir contornos estructurales de la reproducción de los procesos políticos de búsqueda del poder y toma de decisiones colectivamente vinculantes, incluso en la medida en que las decisiones mayoritarias democráticamente deliberadas puedan ser declaradas inconstitucionales. Por otro lado, convierte al código binario «poder/no poder» en relevante para el sistema jurídico. Esto significa que el proceso democrático de toma de decisión política, en el sentido de formación de la mayoría, pasa a constituir una variable estructural de la reproducción de los procedimientos jurídicos, de solución y absorción de conflictos, incluso en la medida en que la producción de normas jurídicas legislativas depende de las decisiones políticas deliberadas democráticamente y tomadas mayoritariamente.

Este acoplamiento estructural se concreta y realiza por medio de procedimientos estatuidos constitucionalmente, esto es, procedimientos judiciales, administrativos, legislativos, electorales y democráticos directos, organizados en una escala que pasa del énfasis en la racionalidad jurídica (procedimientos judiciales) a una prevalencia de la racionalidad política (procedimientos parlamentarios, electorales y plebiscitarios).

De tal forma, existe una legitimación política (democrática) del derecho, y una legitimación jurídica (rule of law) de la política. Evidentemente, la relación estable-

25 LUHMANN, 1990a: 193 y ss.; 1993a: 470 y ss.; 1997: 782 y ss.; 2000a: 389-392. A respecto, cfr. NEVES, 2006 (2000): 95 y ss.

26 LuHMANN, 1997: 108 y ss. y 781 y ss. 
cida por la Constitución como acoplamiento estructural no es de carácter armónico, sino una relación paradojal de complemento y tensión de carácter recíproco. Estado de derecho y derechos fundamentales sin democracia no encuentran garantía alguna para su realización, toda vez que todo modelo de exclusión política pone en jaque los principios jurídicos de legalidad e igualdad, inherentes al Estado de derecho y los derechos fundamentales. A su vez, la democracia sin Estado de derecho y derechos fundamentales degenera en dictadura de la mayoría. Ambas son dimensiones complementarias. Por otro lado, el hecho de que las leyes deliberadas democráticamente y aprobadas por la mayoría sean declaradas inconstitucionales por ofender el Estado de derecho y los derechos fundamentales garantizados constitucionalmente apunta a la tensión permanente que existe entre política democrática y derecho positivo, en el marco del Estado constitucional. Dicha tensión también se presenta, de forma límite, cuando el poder constituyente democrático irrumpe como impulso político para una reconstrucción general y una nueva fundamentación del sistema jurídico estatal. La Constitución como acoplamiento estructural envuelve complementariedad y tensión permanentes, como también rupturas entre política y derecho. Sin embargo, es de tal forma que impide la subordinación estructural de un sistema a otro, especialmente del derecho a la política. Desenvolviendo una relación horizontal u ortogonal entre ambos.

Esta ambivalencia de la Constitución posibilita que pueda ser vista, por un lado, como instancia del sistema político y, por otro lado, como institución del sistema jurídico. En el primer caso, se trata de procesos decisorios de carácter básico en lo que a la construcción y reconstrucción del Estado respecta. Esto es, procesos constituyentes, parlamentarios, administrativos-gubernamentales y electorales o plebiscitarios. La Constitución implica, en tal sentido, una circulación y contracirculación estructural básica entre administración (en el sentido amplio de los procedimientos de los órganos competentes para tomar decisiones políticas y ejecutarlas), política (en un sentido estricto, como procesos de formación de programas partidistas y elecciones entre personas y programas), público como receptor de las decisiones, y pueblo, como lo público en cuanto reacciona activamente ante las decisiones de la administración ${ }^{27}$. En ese concepto político de Constitución, el pueblo clausura el sistema de la política ${ }^{28}$, lo que significa que más allá del pueblo no se puede encontrar legitimación política, sino sólo particularismos y personalismos que niegan o corrompen la democracia. En esta perspectiva, podemos decir que el proceso circular de la democracia y la Constitución en sentido político corresponde a la dimensión política de la Constitución como acoplamiento estructural.

Desde el punto de vista del derecho, la Constitución es la instancia reflexiva más vasta del sistema jurídico, permeando todas sus dimensiones de validez, y abarcando los ámbitos material, temporal, personal y territorial. En cuanto norma(s) de normas, cruza trasversalmente todo el sistema jurídico, dándole consistencia. Introduce, a su vez, un nivel reflexivo del código «lícito/ilícito» en el interior del sistema, que corres-

27 LuHMANN, 2000a: 253 y ss.; cfr. también, aunque sin referencia al «pueblo», 1981a: 42-49; 1981 b: 164.

28 «La clausura del sistema ocurre en el momento en que el colectivo, formado de individuos, grupos y organizaciones, destinatario de ordenes, importunado administrativamente, se vuelve pueblo; en el momento en que la volonté de tous se vuelve volonté générale» (LuHMANN, 2000a: 265). 
ponde al código «constitucional/inconstitucional». A la legalidad se superpone la constitucionalidad. Al respecto, la Constitución en sentido moderno implica la superación de los fundamentos iusnaturalistas, externos al derecho, por un lado, y su autofundamentación constitucional, por el otro. De tal forma, «clausura el sistema jurídico» ${ }^{29}$ estableciendo normativamente los procedimientos básicos mediante los cuales se puede ingresar en el derecho. A través de los procedimientos constitucionales, especialmente por medio del proceso legislativo, la Constitución permite el reingreso de la política en el sistema jurídico. Observando la otra cara de la moneda, la Constitución estructura la apertura cognitiva del sistema jurídico, delimitando su capacidad de aprendizaje y reciclaje, principalmente a través del establecimiento de procedimientos de reforma constitucional. En tal sentido, el núcleo de identidad constitucional (las llamadas cláusulas pétreas) constituye límites insuperables a la capacidad de aprendizaje del ordenamiento respectivo, exigiendo ruptura política en la forma de poder constituyente, para poder reconstruir democráticamente el acoplamiento estructural del Estado de derecho, con un nuevo modelo de Constitución. De esta manera, se establece una nueva relación entre la clausura del sistema jurídico por medio del derecho constitucional, y la clausura del sistema político a través del pueblo.

La Constitución, como acoplamiento estructural, y al mismo tiempo, como mecanismo de diferenciación funcional entre política y derecho o, dicho de otro modo, de desenredar poder y ley, que surgió en la estela de transformaciones radicales de la estructura social en la modernidad, fue factor y producto de una nueva semántica: el Constitucionalismo. Esta semántica constitucionalista se expresa de forma paradigmática en el art. 16 de la Declaración de Derechos del Hombre y del Ciudadano, aprobada por la Asamblea Constituyente Francesa en agosto de 1789: «Toda sociedad en la cual no esté establecida la garantía de los derechos, ni determinada la separación de los poderes, carece de Constitución». En un sentido más amplio, es posible observar la semántica constitucionalista en la concepción de soberanía popular, rule of law y derechos del hombre y de los ciudadanos. Esta semántica, pese a haber servido para consolidar y fortificar las nuevas estructuras políticas y jurídicas, tuvo también un papel simbólico relevante, muchas veces de naturaleza ideológica.

La existencia del voto censitario en casi todos los países llamados constitucionalistas, durante buena parte del siglo XIX, hecho relacionado con la exclusión de grandes grupos del proceso político, constituye una prueba indiscutible de que había un desajuste entre la semántica de la soberanía popular y los límites estructurales de la democracia política. La presencia de la esclavitud hasta la segunda mitad del siglo XIX, así como el apartheid racista que perduró formalmente hasta la decisión del caso Brown v. Board of Education (1954) y materialmente hasta el advenimiento de las acciones afirmativas en los años sesenta, son pruebas incuestionables del profundo desnivel existente entre la semántica constitucionalista y los límites estructurales de los derechos fundamentales en los Estados Unidos. Finalmente, es preciso recordar la restauración francesa, los poderes gubernamentales de la corona británica hasta el inicio del siglo XX, y el colonialismo como límites estructurales al rule of law respecto de la semántica constitucionalista. Entre tanto, ese desfase entre estructuras constituciona-

29 LuHMANN, 1990a: 187. 
les y semántica constitucionalista no debe oscurecer el hecho de que esta semántica, en los Estados de la modernidad central, llevó a la consolidación paulatina de aquellas estructuras. De esta manera, y pese a todas las limitaciones estructurales, en el ámbito de los Estados constitucionales es válida la siguiente autodescripción: «La Constitución clausura el sistema jurídico» y el pueblo clausura el sistema político, autolegitimándolos.

3.

Mientras el pueblo clausura el sistema político y la Constitución clausura el sistema jurídico, la esfera pública abre ambos sistemas o, mejor dicho, es la instancia de heterolegitimación, al presuponer procedimientos políticos y jurídicos susceptibles y abiertos a sus integraciones e influencias. En tal sentido, ella no se confunde con lo «público» como dimensión del sistema político, ni está constituida por sistemas funcionales que forman parte del entorno de la política y del derecho en cuanto sistemas sociales acoplados estructuralmente por la Constitución.

En la concepción luhmanniana no hay espacio para una esfera pública. La relación entre el Estado democrático de derecho - como organización jurídico política autofundamentada en la Constitución como acoplamiento estructural entre derecho y política- y su entorno social, se da básicamente, con los demás sistemas funcionales de la sociedad, mediante la apertura cognitiva o la hetero-referencia de ambos sistemas. En este paradigma teórico se argumenta que tanto el derecho como la política son sistemas operativamente clausurados, destacando que ambos sistemas seleccionan y filtran las influencias de los diversos sistemas funcionales de su entorno, conmutando sentidos. De este modo, lo que es economía se transforma en derecho económico al incorporarse al sistema jurídico, y en política económica al integrarse al sistema político.

Esa conmutación permite afirmar que en el sistema jurídico prevalece la diferencia «lícito/ilícito» ${ }^{30}$ sobre la diferencia «tener/no tener» ${ }^{31}$, y en el sistema político, la diferencia «poder/no poder» ${ }^{32}$ tiene una primacía sobre la diferencia «tener/no tener», incluso en materias que se refieren a la economía. Lo mismo ocurre respecto de los demás sistemas sociales: la ciencia no se confunde con el derecho relativo a la ciencia o con la política científica; el arte, con el derecho o la política referida al arte; la educación, con el derecho o la política educacional; la religión, con el derecho o la política concerniente a la religión; la familia, con el derecho de familia o la política familiar. También en estos casos, los códigos «lícito/ilícito» y «poder/no poder», en los sistemas jurídico y político, respectivamente, tienen primacía sobre los códigos «verdadero/ falso» ${ }^{33}$, «bello/feo» («afinado versus desafinado estéticamente») ${ }^{34}$, «aprobación/reprobación» (en cuanto código-límite de la diferencia gradual «aprender/no aprender», expreso en las calificaciones) $)^{35}$, «trascendente/inmanente» ${ }^{36}$ y sobre el código amoroso

30 LUHMANN, 1986; 1993a: 165 y ss.

31 LUHMANN, 1988b: 181 y ss., 184 y 187 y ss.

32 LUHMANN, 1988a: 56; 1990a: 193.

33 LUHMANN, 1990d: $194 \mathrm{ff}$.

34 LUHMANN, 1996b: 309 y ss.; 1997: 562

35 Cfr. LuHMANN, 2002b: 64 y ss.; 1997: 750; 2004 (1986): 27 y ss.

36 LuHManN, 2002b: 77 y ss. 
(«placer/amor» o «amor/desamor») ${ }^{37}$, que sirve de base a la formación de la familia nuclear moderna ${ }^{38}$, incluso en materias científicas, artísticas, educacionales, religiosas y familiares.

Por supuesto que esto conlleva tensiones, toda vez que las racionalidades jurídica y política, además de relacionarse conflictivamente en el plano constitucional, se confrontan con otras racionalidades, cada una de ellas con pretensiones de universali$\operatorname{dad}^{39}$. Es por esto que la clausura operativa de los sistemas jurídico y político necesita, por medio de los procedimientos constitucionales, asociar la apertura cognitiva de ambos sistemas a las racionalidades sistémico-funcionales que circulan en el entorno del Estado democrático de derecho.

La consistencia jurídico-constitucional del derecho (la constitucionalidad y la legalidad) tiene que ser asociada a la adecuación social de las normas jurídicas. Mientras tanto, la consistencia democrático-constitucional (la «soberanía del pueblo») del sistema político precisa ser compatibilizada con la adecuación social de las decisiones políticas. Esto lleva a paradojas que no pueden superarse o solucionarse de forma definitiva, pero que sí pueden esquivarse o solucionarse en situaciones concretas y momentos específicos. ¿Cómo sobrellevar la reducción del equilibrio entre consistencia democrática y adecuación social evitando, por una parte, «la democracia jacobina», que absolutiza la llamada «voluntad del pueblo»y, por tanto, conduce a una «soberanía autista del pueblo»y, por otra parte, los particularismos de los intereses concretos, enemigos de la «soberanía del pueblo», con la clausura del sistema político?

Naturalmente, también en el modelo luhmanniano la política y el derecho, en cuanto sistemas acoplados estructuralmente por medio de la Constitución, se relacionan con los componentes de su entorno social que no son construidos sistémicofuncionalmente. Así las cosas, ambos sistemas se encuentran en relación con la moral, pero la moral en un sentido luhmanniano, es decir, como una forma especializada de comunicación que funciona en base al código binario «consideración/desprecio» ${ }^{40}, \mathrm{y}$ que no constituye un sistema funcional, ni un sistema de interacción (aquellos que son construidos en base a la diferencia «presencia/ausencia»), ni una organización (sistema construido en base a la diferencia «miembro/no miembro») ${ }^{41}$. Por supuesto que la moral se construye a través de interacciones y es reproducida difusamente en las organizaciones y en los sistemas funcionales de la sociedad, pero ella misma no constituye un sistema. Para aclarar el punto, podemos decir que forma parte del mundo de la vida, tomando este último concepto y alejándonos de la vertiente luhmanniana, como aquel espacio social no estructurado sistémicamente. Asimismo, la moral puede transformarse en «ética» de un sistema funcional o de una organización ${ }^{42}$; con todo, en este caso, la diferencia binaria entre consideración y desprecio en lo que respecta a las personas, queda subordinada al código binario y a los criterios/programas del respectivo sistema funcional, o a la diferencia constitutiva de la correspondiente organización (miembro/

\footnotetext{
37 LUHMANN, 1990c (1982): 107 y ss.; 1997: 750.

38 Cfr. LUHMANN, 1997: 730 y ss.; 1990c (1982): 183 y ss.

9 Cfr. Teubner, 1996; Fischer-Lescano y Teubner, 2006.

40 LuHManN, 1990b, 1993b.

41 LUHMANN, 1975; 1997: 812-847.

42 Cfr. LuHManN, 1999: 247.
} 
no miembro), y a los programas de ésta. El hecho es que, en principio, falta generalización de programas o criterios morales en la complejidad de la sociedad moderna, lo que imposibilita la existencia de un sistema moral. El problema moral se vuelve más bien una cuestión de sabotaje o corrupción de los códigos sistémicos ${ }^{43}$. Por tanto, la relación de la moral con el sistema jurídico y político, acoplados estructuralmente por la Constitución, ocurre de manera difusa y puntual.

Otro ejemplo de relación del sistema jurídico y el sistema político con parte del entorno no estructurado sistémicamente son las protestas. Estas no se confunden con la oposición en el ámbito de la política, ni con pretensiones de reforma ${ }^{44}$. En palabras de LUHMANN, la paradoja de las protestas reside en que ellas ocurren «en la sociedad [...], pero contra ésta» ${ }^{45}$. Las protestas, de igual forma que la moral, no constituyen un sistema funcional, ni una interacción, ni una organización ${ }^{46}$, pese a que no existan protestas sin interacción y ellas se reproduzcan también de manera difusa en el ámbito de las organizaciones y los sistemas funcionales. Por su parte, tampoco existen criterios o programas generalizados para las protestas, toda vez que ellas dependen de la temática y de la situación concreta. Se podría observar un código binario en la forma de comunicación «protesta»: la diferencia «en contra/a favor», dirigida a la sociedad. Dicho código se distingue del código «consideración/desprecio», dirigido primariamente a las personas. No obstante, hay protestas moralizadas y hay morales de protesta. Por carecer de estructura sistémica y, por tanto, de programas generalizados, las protestas se relacionan difusa y puntualmente con la Constitución como acoplamiento estructural entre política y derecho.

Aunque la teoría sistémica de LUHMANN admita la relevancia de la moral y las protestas como formas de comunicación no estructuradas sistémicamente, tanto para la sociedad en general como para la política y el derecho acoplados constitucionalmente, dicho paradigma no acepta el concepto de esfera pública como ámbito de comunicaciones no estructurado sistémicamente; cuando más, contempla el concepto «público» como dimensión funcional del sistema político. Tal ortodoxia sistémica vuelve difícil el desenvolvimiento de ciertos análisis más finos de la sociedad supercompleja del presente.

La negación de la esfera pública, como la conexión más relevante de las comunicaciones no estructuradas sistémicamente en relación a la heterolegitimación de la política y el derecho como sistemas acoplados constitucionalmente, tiene su origen en un prejuicio sistémico ${ }^{47}$. La esfera pública, así como la moral y las protestas, no constituyen un sistema funcional, ni una interacción, ni una organización, pese a la imposibilidad de la existencia de una esfera pública sin interacciones, y al hecho de que las organizaciones actúen en ella, y los sistemas se nutran con sus sustratos de sentido. Dentro de la esfera pública, es posible encontrar moral y protestas, pero ambos

43 Luhmann, 1997: 1043. Cfr. Teubner, 1998: 21 y ss.; 1996: 218.

44 LUHMANN, 1996a: 204 y 206.

45 LUHMANN, 1996a: 204.

46 Luhmann, 1996a: 202.

47 En el ámbito de la teoría de sistemas, STісншен (2002: 60 y ss.), de forma diversa, define la esfera pública como el «entorno interno» de un sistema funcional y, consecuentemente, la esfera pública mundial como el «entorno interno» de la política mundial. 
pasan a ser apenas formas de comunicación en su interior. Esta idea podría sugerir que la esfera pública corresponde a un megasistema, o a un centro de la sociedad, no obstante, no es nada de eso. Si la comparamos con la moral, o con las protestas, que poseen un código binario, resulta aún más difícil encuadrarla en el concepto de sistema. En la esfera pública se mezclan, de forma transversal, una diversidad desestructurada de diferencias binarias. Tampoco se puede afirmar que corresponda al centro de la sociedad moderna, multicentrica. En el sentido aquí utilizado, se muestra apenas como relevante para el entorno social de los procedimientos jurídicos y políticos constitucionalmente estructurados, influyendo en la producción o concreción de normas jurídicas, y en la toma o ejecución de decisiones políticas. Me parece que el prejuicio de la teoría de sistemas en relación con el concepto de esfera pública proviene de la confusión con el concepto análogo, desarrollado en el seno de la teoría habermasiana de la sociedad y el Estado democrático de derecho, el que sin duda posee una sobrecarga normativa.

Para HABERMAS, la esfera pública es el espacio en que ocurre la generalización de pretensiones de validez compartidas de forma ingenua, en las interacciones concretas de lo cotidiano, dentro del horizonte que constituye el mundo de la vida ${ }^{48}$. En dicho contexto, el mundo de la vida es definido como el «horizonte en que se mueven los agentes comunicativos» ${ }^{49}$, orientados hacia el consenso, sea como entendimiento o como un acuerdo ${ }^{50}$; por su parte, las pretensiones de validez corresponden a: la sinceridad, referida al mundo subjetivo; la verdad, relativa al mundo objetivo; y la rectitud (validez normativa), relacionada con el mundo social ${ }^{51}$. En gran parte, dichas pretensiones de validez (especialmente, la verdad y la validez normativa) se generalizan en la esfera pública, por medio de los discursos (teórico o práctico). Dichos discursos se inician cuando un actor cuestiona de forma concreta la pretensión de validez de una acción o un acto de habla, compartido ingenuamente en el mundo de la vida, exigiendo por parte del agente comunicativo una argumentación y fundamentación de carácter racional ${ }^{52}$. La introducción de un disenso, por medio de estos discursos, posibilita, mediante convencimiento, alcanzar un consenso (sobre nuevas bases), que será reintegrado al mundo de la vida. No obstante, es importante señalar, que no es sólo a través del discurso como se produce la generalización de las pretensiones de validez en la esfera pública, sino también por medio de las instituciones. Además de esto, HABERMAS no desconoce que en la esfera pública (así como en el mundo de la vida), hay acciones estratégicas orientadas al éxito. La misma existencia de una «esfera pública pre-estructurada y dominada por los medios de masa», que «se transforma en una arena tomada por el poder (einer vermachteten Arena) ${ }^{53}$, implica que acciones estratégicas hagan parte de ella. Pero la fuerza legitimadora de la esfera pública, tanto para la política como para el derecho, en el marco del Estado constitucional, reside, conforme al modelo habermasiano, en la dimensión de las acciones y de los discursos orientados

48 Cfr. HABERMAS, 1982: vol. 2, 274 y ss.

49 Habermas, 1982: vol. 2, 182.

50 HABERMAS, 1982: vol. 2, 274 y ss.

51 Cfr., por ex., Habermas, 1982: vol. 1, 427 y ss.; 1983: 147 y ss.; 1986: 137 y ss., 426 y ss., 462 y ss. y 588 y ss

52 Cfr. Habermas, 1986: 130 y ss.; 1978: 25; 1983: 116; 1991: 162.

53 Habermas, 1990: 28. 
hacia el consenso. HABERMAS se refiere entonces a una «esfera pública política» ${ }^{54}$, cuyo potencial legitimador consiste en la capacidad de enfrentar los problemas de forma discursiva (esto es, racionalmente orientada al consenso) y, de no ser posible, por medio de negociaciones reguladas procedimentalmente ${ }^{55}$. En esta perspectiva, la esfera pública no tiene un portador o un sujeto, sino que es construida por una pluralidad de discursos y negociaciones racionales que poseen fuerza legitimadora para los procedimientos constitucionales ${ }^{56}$. No obstante, en el modelo habermasiano, el concepto de esfera pública no tiene un carácter «empírico», sino «normativo», y resulta discutible si el sentido de la esfera pública en el Estado constitucional, incluso desde la perspectiva «normativa», consiste en erigir «resultados racionales», o sea, consensuales.

Me parece que, mientras que los límites del modelo luhmanniano residen en el desprecio del concepto de esfera pública como espacio sistémicamente desestructurado que contorna los procedimientos constitucionales, el problema de la idea habermasiana radica en que está sobrecargada por la noción de una razón discursiva, orientada al consenso. La concepción de HABERMAS resulta inapropiada para la auto-reflexión y auto-descripción de la reproducción de las estructuras (cognitivas y normativas), y las operaciones de la sociedad contemporánea, caracterizada por una heterogeneidad de personas y grupos (valores, expectativas, intereses y discursos de carácter diverso), pero sobre todo, por la complejidad sistémica. En tal sentido, y a pesar de reconocer la relevancia del concepto de esfera pública para la comprensión de la heterolegitimación de los procedimientos sistémicos de la política y el derecho en el contexto del Estado constitucional, ofrezco una versión diferente y «reconstruida», que pretende ser una auto-reflexión y auto-descripción más apropiada de aquel espacio «no organizado» ${ }^{57}$ de reproducción de la sociedad ${ }^{58}$.

La esfera pública está formada por el conjunto de valores, intereses, expectativas y discursos que emergen de los diversos sistemas funcionales y del denominado «mundo de la vida» (operacionalizado a través de las innumerables interacciones cotidianas desestructuradas tanto sistémico-funcionalmente, como sistémico-organizacionalmente, y reproducido por medio del lenguaje natural no especializado), y que pierden tanto su relevancia de sentido específico, como las respectivas conexiones sistémicas de comunicaciones y referencias concretas del mundo de la vida, con la pretensión y la exigencia de influir en los procedimientos de producción y concreción normativa, así como también los de toma y ejecución de decisiones políticas en el Estado constitucional. Los valores, ya sean aquellos valores-preferencia relativos a aquello que un grupo o individuo considera bueno para su vida ${ }^{59}$, o aquellos valores-identidad, correspondientes a autoevidencias incuestionables por aquellos grupos o personas que los asumen ${ }^{60}$, se separan de las estructuras y operaciones sistémico-funcionales, y de la reproducción concreta del mundo de la vida, introduciéndose a su vez en un espacio de divergencias alrededor de procedimientos jurídicos y políticos. Asimismo, los inte-

54 HaBERMAS, 1990: 38 y ss.

5 Cfr. HABERMAS, 1992: 201-207.

56 Cfr. HABERMAS, 1990: 38 y 43 y ss.; 1992: 607.

57 HABERMAS se refiere también a una «esfera pública no organizada» (1990: 43).

58 Cfr. NeVES, 2006 (2000): 123 y ss.

59 Habermas, 1992: 190.

60 LuHMANN, 1998: 349; 2000a: 193. 
reses, en cuanto estructura de acción encaminada a la relación eficiente entre medios y fines, se desligan de las respectivas comunicaciones orientadas sistémicamente, o modeladas por las interacciones en el mundo de la vida, entrando en conflicto respecto de procedimientos normativos y decisorios.

Por su parte, la contradicción existente entre las expectativas de comportamiento, como modelos estructurales de conducta que ego (vivencia) construye en relación a alter (acción), se desacoplan de sus especificidades sistémicas y de los particularismos de las interacciones cotidianas con el objetivo de estabilizarse y generalizarse como normas jurídicas (expectativas normativas «congruentemente generalizadas») o decisiones políticas (colectivamente vinculantes). Finalmente, como juegos del lenguaje en que circulan contrariamente valores, intereses y expectativas, altamente diversos, los discursos — que al contrario de la impersonalidad de los sistemas (en los cuales las personas son referidas apenas como «direcciones de procesos de comunicación» $\left.{ }^{61}\right)$, pueden ser atribuidos a personas y grupos, como sus eventuales portadores - se desprenden de programas o criterios sistémico-funcionales, y de los modelos de la interacción cotidiana del mundo de la vida, introduciéndose en la esfera pública «desorganizada», desestructurada, en divergencias permanentes con otros discursos, respecto del rumbo de los procedimientos normativos y decisorios del Estado constitucional, a los cuales procuran incorporarse como modelos de regulación o decisión.

Comprendida de tal forma, la esfera pública corresponde a un área de tensión entre derecho y política como sistemas funcionales, acoplados estructuralmente por la Constitución, por un lado, y los demás sistemas funcionales y el mundo de la vida, por el otro. En ella, no sólo existen divergencias entre los valores, expectativas, intereses y discursos referentes a personas y grupos, sino que, principalmente, se afirma el disenso entre las exigencias y pretensiones que emergen de los diversos sistemas funcionales en relación a los procedimientos de los sistemas jurídico y político. En tal sentido, cabe caracterizarla como arena del disenso. Por ejemplo, más allá del disenso existente entre personas y grupos favorables o contrarios a un uso más amplio de la tecnología genética, a través de la discusión de dicho asunto en la esfera pública, se intensifica el disenso estructural entre las pretensiones y exigencias contradictorias que emergen de la economía, la ciencia, la educación y la religión, frente a los respectivos procedimientos jurídico-normativos y político-decisorios. Sin embargo, esto no debe confundirse con conflictos intersistémicos. En los debates que ocurren en la esfera pública, entre pretensiones normativas y exigencias decisorias que emergen de la ciencia, el arte, la economía, la religión, etc., no se trata de hacer investigación, crear obras artísticas, pagar o rezar, sino de comunicaciones que, separadas de esos sistemas funcionales, intentan influir en los procedimientos políticos y jurídicos, buscando soluciones que se correspondan de la mejor forma con la reproducción de los respectivos sistemas. Pese a que existan divergencias entre los «representantes» de cada uno de los sistemas funcionales en la esfera pública (disenso referido a personas y grupos), evidentemente las posiciones de un «representante» de la economía (por ejemplo, un empresario del sector farmacológico), un «representante» de la medicina, otro de la ciencia propiamente tal o del sistema educacional, y otro de la religión, serán diferentes y tenderán al

61 LuHManN, 1989: 367, nota 11. 
disenso, en el marco de un debate respecto de los procedimientos jurídicos y políticos destinados a normar o decidir sobre la tecnología genética, aborto inducido, recursos destinados a la salud, ciencia, educación, etc. Cada uno de ellos sin practicar las comunicaciones que son propias del sistema que está «representando» (empresario fuera de la economía, médico fuera de la medicina, científico fuera de la ciencia, maestro fuera de la educación, religioso fuera de la religión) tiende a defender la adopción de normas jurídicas y decisiones políticas que respondan adecuadamente a la racionalidad especifica del sistema por él «representado». De esta manera, los conflictos intersistémicos de racionalidad son transformados en la esfera pública en disenso estructural en torno a los procedimientos de producción y concreción normativa del derecho, y de toma de decisión y ejecución de decisiones colectivamente vinculantes en la política.

La esfera pública pluralista no constituye, de manera alguna, un mega-acoplamiento estructural, vinculando los demás sistemas funcionales a la política y al derecho. Como espacio desestructurado o «desorganizado» de la reproducción social en torno a la política y el derecho, es incapaz de canalizar influencias y afectaciones recíprocas entre sistemas. Tampoco constituye el centro de la sociedad. La esfera pública es apenas, en relación a los procedimientos políticos y jurídicos establecidos constitucionalmente en el ámbito del Estado como organización territorialmente delimitada de la sociedad mundial, un entorno no estructurado sistémicamente, pero con relevancia y fuerza legitimadora. Incluso podría afirmarse que en torno a otros sistemas funcionales - economía, educación, religión, etc.— se construyen otras «esferas públicas». Imaginemos, por ejemplo, un boicot «público» a determinado producto o empresa, no atribuible a un sistema funcional u organizacional, y sin pretensión alguna de influir en los procedimientos jurídicos o decisiones políticas del Estado constitucional. No se trata, en dicho caso, de la «esfera pública política o jurídica», referente a los procedimientos constitucionales del Estado.

Asociado de cierta forma al contexto descrito, cabe distinguir el espacio no estructurado sistémicamente, de lucha y búsqueda de aseguramiento de la autonomía de los sistemas funcionales y reproducción del mundo de la vida, que en el lenguaje común es denominado como «sociedad civil» (que si bien no se confunde con las comunicaciones de los respectivos sistemas funcionales, se localiza en sus entornos), y la esfera pública como espacio en que se lucha por determinadas regulaciones jurídicas y decisiones políticas, a partir de las exigencias emergentes de los sistemas funcionales y del mundo de la vida, con pretensión heterolegitimadora de los procedimientos sistémicos de la política y del derecho. Pese a estar desestructurada y «desorganizada», en la esfera pública heterolegitimadora del Estado constitucional es posible encontrar organizaciones de diverso tipo, con las que se desarrolla una relación compleja, toda vez que, si la esfera pública queda subordinada a alguna de ellas, su condición de espacio heterolegitimador se ve descaracterizado. De igual forma, es incorrecto vincular la esfera pública con un único sistema funcional. Incluso en caso de admitir que se encuentra fuertemente intermediada por los medios de comunicación de masas, sobre todo los electrónicos, cabe considerar que la esfera pública va mucho más allá de los mass media.

Por otra parte, resulta un hecho incuestionable que, a pesar de que (a diferencia de los demás sistemas funcionales) los medios de masas cortan de forma transversal la es- 
fera pública llegando incluso muchas veces a manipularla, también son forzados a responder contra sus propios intereses, las afectaciones provenientes de la esfera pública. Por ejemplo, las protestas reiteradas y crecientes que tienen lugar en las calles pueden ser llevadas a los noticiarios después de una larga reacción de los medios electrónicos de comunicación, que en tal situación actúan como vehículo de la esfera pública que protesta. Los mass media, sin duda, constituyen un importante medio de fortificación de la influencia de la esfera pública desorganizada en los procedimientos jurídicos y políticos del Estado constitucional, sin embargo ésta posee un carácter mucho más vasto que aquéllos.

Es importante advertir que la fuerza heterolegitimadora de la esfera pública en lo que respecta a los procedimientos del Estado constitucional no puede ser pensada unilateralmente a partir de los condicionamientos externos de los sistemas de la política y el derecho. Es imprescindible que los procedimientos jurídicos y políticos estén estructurados de tal forma que puedan absorber el disenso de la esfera pública, sin suprimirlo, y promoviendo su emergencia. Esto significa que, a pesar de que los procedimientos constitucionales tienen una fuerte función selectiva frente a la pluralidad compleja de valores, intereses, expectativas y discursos que se relacionan disensualmente en la esfera pública, sólo encuentran su heterolegitimación si permanecen abiertos al disenso presente en dicha esfera.

Esta paradoja entre la clausura selectiva intrínseca, y la reproducción autopoietica del derecho y la política como sistemas acoplados estructuralmente por la Constitución, por un lado, y la dependencia de una heterolegitimación de los procedimientos en la esfera pública (no sólo como apertura cognitiva respecto del entorno), por el otro, es indispensable para la propia continuidad de los Estados constitucionales en las condiciones de elevada contingencia de la sociedad mundial moderna, siendo ellos mismos expresión de aquella contingencia. Por tanto, no es una paradoja superable ni susceptible de ser solucionada de forma definitiva, pero sí puede ser abordada, controlada e incluso solucionada en situaciones concretas. Esto implica rechazar cualquier consenso respecto de los contenidos como patrón legitimador de los procedimientos constitucionales, sea como exigencia funcional, o como exigencia normativa. Precisamente, el sentido de dichos procedimientos es garantizar la permanencia del disenso en la esfera pública pluralista de una sociedad heterogénea (en relación a la divergencia de valores, intereses, expectativas y discursos que orientan la comunicación y acción de las personas y grupos) y compleja (en lo que respecta a la diversidad siempre en conflicto de las racionalidades sistémicas).

Por medio de la clausura selectiva, el disenso es absorbido por procedimientos concretos, pero la heterolegitimación de dichos procedimientos sólo ocurre si no provocan una clausura de la política y el derecho frente al futuro contingente. La apertura de dichos sistemas respecto de dicha contingencia ocurre exactamente en la medida en que no reprimen el disenso que permanece en la esfera pública y, a su vez, viabilizan y estimulan su desenvolvimiento. Esto significa afirmar, por ejemplo, que el sentido del procedimiento electoral, aun partiendo de un modelo «normativo», no corresponde a que se alcance un resultado consensual entre los adversarios políticos; por el contrario, los resultados de los procedimientos electorales, inclusive cuando se respetan rigurosamente las reglas del juego, tienden a intensificar el disenso. De ma- 
nera análoga, el sentido «normativo» o funcional de un procedimiento jurisdiccional no consiste en que se llegue a un resultado consensual entre las partes; muy por el contrario, el resultado de un procedimiento jurisdiccional, principalmente del control de constitucionalidad (pensemos en el caso de la llamada «interrupción terapéutica del embarazo» en caso de anencefalia del feto y su tipificación, o no, como crimen de aborto), tiende a fortificar el disenso en la respectiva esfera pública. Esto significa que, en futuras eventualidades procedimentales, las expectativas rechazadas en el presente, puedan, a partir de rearticulaciones en la esfera pública, prevalecer inclusive por medio de otras formas procedimentales (por ejemplo, cambio legislativo o reforma constitucional frente a la insatisfacción en relación a la adjudicación constitucional o legal, impeachment del presidente de la República, declaración de inconstitucionalidad de la ley). De esta manera, los procedimientos constitucionales aseguran, en el contexto territorialmente delimitado de los Estados democráticos de derecho, la permanencia del disenso en las respectivas esferas públicas de la sociedad mundial, altamente compleja y contingente.

El disenso en el contenido presupone un consenso procedimental como «condición de posibilidad» del Estado constitucional. La base consensual respecto de los procedimientos es impuesta con la finalidad de asegurar el respeto a las diferencias y la complejidad sistémica en la esfera pública. Al excluirse de ésta ciertos grupos y personas, o exigencias que emergen de un determinado sistema funcional, se produce una represión del disenso y los procedimientos pierden su base consensual. Es cierto que persiste el problema paradojal de la necesidad, en ciertas circunstancias muy excepcionales, de excluir procedimentalmente intereses, valores y discursos dirigidos a la negación de la heterogeneidad cultural, y de la complejidad sistémica de la sociedad; precisamente, porque ellos se orientan directamente a destruir la esfera pública pluralista y el orden disensual intermediado por los procedimientos. Tal esfera sólo se construye y mantiene si hay una base consensual sobre los procedimientos. En esta perspectiva, cabe sostener que el Estado constitucional envuelve y exige una intermediación del disenso en los contenidos y del consenso procedimental, presuponiendo para ello una esfera pública pluralista y «universal» (incluyente) articulada en torno a los procedimientos ${ }^{62}$.

4.

La esfera pública presupone inclusión de las personas en los sistemas funcionales y reconocimiento reciproco en el ámbito de las interacciones, ¿pero cómo definir y relacionar inclusión y reconocimiento?

Para que la inclusión no se trasforme en un mero lugar común de la retórica de lo políticamente correcto, necesita ser definida de forma precisa. En el ámbito de la teoría de sistemas, es posible rastrear el término en PARSONS, a propósito de la cuestión de los negros en Estados Unidos ${ }^{63}$. En aquel contexto, el sociólogo norteamericano recurre a las formulaciones de MARSHALL sobre el desarrollo de la ciudadanía en los siglos XIX

62 Cfr. Neves, 2006 (2000): 136 y ss.

63 PARSONS, 1994 (1965). 
y XX, que va desde los derechos civiles, pasando por los derechos políticos, a los derechos sociales ${ }^{64}$. Al retomar dicha discusión, LUHMANN propone un concepto de inclusión en términos precisos, para referirse a aquellas situaciones en que las personas dependen de las prestaciones de los sistemas sociales y tienen acceso a ellas. En dicho sentido, el concepto contiene dos polos, la dependencia y el acceso $0^{65}$. En el marco de esta formulación conceptual, la sociedad moderna, al contrario de formaciones sociales anteriores, se caracteriza por la inclusión de toda la población en los sistemas funcionales, o por lo menos de una parte creciente de ella ${ }^{66}$. Explícitamente, de acuerdo con LUHMANN, es posible afirmar que en la sociedad moderna prevalecería, tanto en el plano de la semántica como en el de la estructura, la preferencia por la inclusión. Esta posición, discutible, que critiqué en trabajos anteriores ${ }^{67}$, teniendo en vista principalmente la situación de los Estados en la modernidad periférica, fue totalmente dejada de lado en la obra tardía de LUHMANN.

En una posterior revisión a su posición en lo que respecta a la diferencia «inclusión/exclusión» ${ }^{68}$, LUHMANN señala, que ella funciona como una metadiferencia o metacódigo, que mediatiza los códigos de todos los sistemas funcionales de la sociedad mundial contemporánea ${ }^{69}$. En este nuevo modelo conceptual, ya no se considera la dependencia y el acceso como dos aspectos del concepto de inclusión, y define la inclusión misma (lado interno de la diferencia inclusión/exclusión) como «posibilidad de consideración social de personas», pretendiendo así «sustituir» por el tema de la integración social concerniente a la relación entre personas y sistemas sociales, «la distinción inclusión/exclusión» ${ }^{70}$. De la inclusión se distingue la integración (sistémica), comprendida «como reducción de los grados de libertad de los subsistemas» o «como limitación de los grados de libertad para las selecciones» ${ }^{71} \mathrm{y}$, por tanto, negativamente en cuanto dependencia, no como acceso $^{72}$. En esta perspectiva, LUHMANN propone (en su obra tardía) la diferencia entre «sector de inclusión» (en el cual «los hombres cuentan como personas») y «sector de exclusión» (en el cual «los hombres no son más percibidos como personas, sino como cuerpos»), sosteniendo que el primero sería menos integrado y el segundo sobreintegrado ${ }^{73}$. Con todo, LuHMANN sólo habla de «apenas integración negativa» en el sector de exclusión y de «integración de individuo y sociedad» en el sector de la inclusión ${ }^{74}$, así como de «personas y grupos no integrables» en referencia a la exclusión ${ }^{75}$. De cualquier forma, en su obra tardía, LuHMANN usa la expresión «integración» en relación al problema de la inclusión/exclusión, sin que haya univocidad al respecto.

${ }^{64}$ Parsons, 1971: 21 y ss. y 81 ss.; 1994 (1965): 146 y ss. Cfr. MARShall, 1976 (1949-1950): 71 y ss.; BENDIX, 1969 (1964): 92 y ss.

${ }^{65}$ LuHMANN, 1981a: 25.

${ }^{66}$ Cfr. LuHMANN, 1981a: 26 y ss.

67 Neves, 1992: 94 y ss., 155 y ss. y 164 y ss.; 1994.

68 Luhmann, 1997: 169 y ss., y 618-634; 1995a; 1995b: 146 y ss.; 1993 a: 582 y ss.; 2000a: 427 y ss.; 2000b:

233 y ss., 242 y ss. y 301 y ss.

69 LUHMANN, 1997: 632; 1993a: 583.

70 LUHMANN, 1997: 619 y ss.

${ }_{71}$ LUHMANN, 1997: 603 y 631.

72 LuHMAnN, 1997: 618 y ss.

73 Luhmann, 1993 a: 584 y ss.; 1997: 631 y ss.; 1995a: 259 y ss. (262).

74 LuHManN, 1995b: 148.

75 LuHManN, 1997: 621. 
Es necesario hacer presente dos advertencias relativas a lo expuesto en líneas precedentes sobre inclusión/exclusión, que de cierta manera fueron respuestas a mis críticas al modelo anterior de inclusión como característica de la sociedad moderna ${ }^{76}$. En primer lugar, cabe observar, que para ser consecuente con la afirmación de que «inclusión/exclusión» sirve como metacódigo que mediatiza todos las otras diferencias binarias, es preciso admitir — radicalizando la tesis_ que la sociedad mundial se diferencia primariamente de acuerdo con esta metadiferencia ${ }^{77}$; en el caso de la «inclusión/exclusión» versus la diferencia (orientada funcionalmente) «sistema/entorno», no obstante, se trata de diferencias que actúan simultáneamente en la sociedad mundial contemporánea. En segundo lugar, me parece más fructífero definir la inclusión como dependencia y acceso a los sistemas, reconociendo sus límites en la sociedad mundial, especialmente en la modernidad periférica. Tal como lo he formulado, en la modernidad periférica existen relaciones de subintegración (o subinclusión) y sobreintegración (o sobreinclusión), que implican inclusión insuficiente, sea por falta de acceso (de integración positiva) o de dependencia (de integración negativa) ${ }^{78}$, respectivamente. Constituyendo posiciones jerárquicas condicionadas fácticamente (no clasificaciones basadas en principio), a saber, el hecho de ser integrado (o incluido) en los sistemas funcionales «por abajo» o «por arriba». En ambas direcciones (para «abajo» o para «arriba») se trata de limitación y unilateralidad en la capacidad de imputación de los sistemas sociales en sus referencias a personas.

En el ámbito del derecho, esto significa que los sobreintegrados o sobreincluidos tienen acceso a los derechos (y por tanto, a los mecanismos y garantías jurídicas), sin vincularse efectivamente a los deberes y responsabilidades impuestas por el sistema jurídico; los subintegrados o subincluidos, al contrario, no disponen de acceso a los derechos, mecanismos y garantías jurídicas, aunque permanezcan rigurosamente subordinados a los deberes, responsabilidades y penas restrictivas de libertad. Por consiguiente, tanto los subincluidos como los sobreincluidos carecen de ciudadanía, que en cuanto mecanismo político-jurídico de inclusión social (en el sentido técnico-jurídico de ser miembro de un Estado como organización: «nacionalidad») ${ }^{79}$, presupone igualdad no sólo en relación a los derechos, sino también respecto de los deberes ${ }^{80}$.

76 Cfr. LuHMAnN, 1992: 2 y ss.; 1993a: 25, 81, 194, 478 y ss. y 584; 1995a: 261; 1997: 169, 632, 787, 806 y $810 ; 2000 a: 356$ y 428.

77 STICHWEH (1997) defiende que esta conclusión estaría presente en la propia obra de LUHMANN: «En Niklas Luhmann, se encuentra la tesis de que la diferenciación de la inclusión y la exclusión se impone como diferenciación primaria del sistema de la sociedad, prevaleciendo sobre la diferenciación funcional» (132). Él se refiere a LUHMANN, 1995a. No obstante, el mismo LuHMANN insistía —pese a caracterizar la diferencia «inclusión/exclusión» como metadiferencia - en el primado de la diferenciación mundial del presente ( $c f r$. LuHMANN, 1997: 743 y ss.; 1994: 4 y ss.; 1993a: 572).

78 En caso de que, basándose en PETERS (1993: 92), se pretenda conceptualizar la integración social como «una relación exitosa de libertad y vínculo», se puede definir (en el sentido aquí propuesto) subintegración como «vínculo» sin libertad (o mejor dicho, «vínculo» rígido y «libertad» restringida), y sobreintegración como «libertad» sin «vínculo» (o más precisamente, «vínculo» flexible y «libertad» amplia) de las personas respecto de los sistemas sociales.

${ }_{79}$ En una perspectiva sistémica, Holz (2000: 191 y ss.) propone una diferencia entre inclusión en la sociedad (o en sus sistemas funcionales) y ciudadanía como cualidad de miembro de un Estado («nacionalidad») ( $c f r$ también BORA, 2002: 76). De esta manera, desconoce la distinción entre el sentido técnico-jurídico de la ciudadanía como «nacionalidad» (cualidad de miembro de un Estado en cuanto organización), y el sentido sociológico de ciudadanía, es decir, como institución político-jurídica de inclusión en la sociedad.

${ }^{80}$ Cfr. Marshall, 1976 (1949-1950): 112 y ss. 
Si la inclusión como dependencia y acceso a las prestaciones de diversos sistemas sociales no es generalizada en el ámbito territorial del respectivo Estado, existe entonces fragilidad de la esfera pública universalista y pluralista como espacio de heterolegitimación de los procedimientos del Estado constitucional. En caso de generalizarse formas de exclusión, sea por falta de acceso o por privilegios de determinados grupos, se puede decir que nos encontramos frente a una esfera pública inexistente o, por lo menos, frente a una esfera pública restringida, con fuerza legitimadora muy limitada. Esta situación es especialmente relevante cuando se trata en específico de exclusión de la política y del derecho, esto es, de ausencia efectiva de ciudadanía como institución generalizada de inclusión político-jurídica. En este caso, no están presentes las condiciones para la intermediación del disenso en el contenido por el consenso procedimental, ni se puede compatibilizar la selectividad procedimental consistente (autolegitimación) con la apertura de los procedimientos sistémicos frente al futuro contingente, relacionando la permanencia y, eventualmente, la fortificación del disenso en la esfera pública, a cada absorción de éste por dichos procedimientos. Por otra parte, en un orden de procedimientos jurídico-políticos excluyentes (totalitario o autoritario), o en una estructura social con prevalencia generalizada de la preferencia por exclusión, el disenso es desconocido o negado, o su emergencia reprimida.

En relación al otro presupuesto de la esfera pública, esto es, el reconocimiento, cabe efectuar algunos esclarecimientos en una perspectiva de reconstrucción a partir de la teoría de sistemas. A diferencia de la inclusión, que se refiere a la relación de dependencia y acceso de las personas a los sistemas funcionales y, por tanto, a la sociedad como sistema social más amplio, el reconocimiento es un problema que surge primariamente en el plano de la «doble contingencia» ${ }^{81}$ presente en la relación de observación reciproca de ego y alter en la interacción. En primer lugar, no se desconoce aquí que la cuestión de la doble contingencia en la teoría sistémica luhmanniana no se restringe a la interacción, en la cual los polos ego y alter remiten a (aunque no se confundan con) personas, teniendo en cuenta que alter y ego pueden remitir también a sistemas sociales ${ }^{82}$. En segundo lugar, cabe advertir que la doble contingencia en la interacción supone observación reciproca de personas en cuanto construcciones sociales o direcciones de comunicación, sin tratarse de una relación interpsíquica entre hombres, como ocurre en las teorías dominantes de reconocimiento ${ }^{83}$. Como black boxes, ego y alter remiten en la interacción a personas, cuyas actuaciones y vivencias permanecen indeterminados. Finalmente, debe observarse que la cuestión del reconocimiento no se confunde con el tema de la doble contingencia, constituyendo apenas uno de los innumerables problemas que emergen en el plano de la doble contingencia de la interacción.

81 LuHMAnN, 1987a (1984): 148 y ss.; 1987 b (1972): 32 y ss.; 2002a: 315 y ss. El concepto de doble contingencia se remonta, de acuerdo con LUHMANN [1987a (1984): 148; 2002a: 317], a Talcott PARSONS y un equipo de investigadores vinculados a él. Cfr. PARSONS et al., 1951: 16; PARSONS, 1968: 436.

82 LuHManN, 1987a (1984): 152 y 155.

83 Cfr., en la línea de MEAD, Honneth, 1994: 114 y ss., cuya teoría del reconocimiento intersubjetivo se remonta a la concepción hegeliana de «lucha por el reconocimiento» [1994: 54 y ss.; cfr. HEGEL, 1967 (18051806): 200 y ss.]. Según HoNNETH (1994: 12), el modelo de una «lucha por el reconocimiento» habría perdido su significado teórico en la Fenomenología del Espíritu [cfr. HEGEL, 1988 (1807): 127 y ss.; HoNNETH, 1994: 104 y ss.]. Para la comprensión del debate sobre el reconocimiento, vid. TAYLOR, 1993; 1995: 52 y ss.; FRASER, 2004; FRASER/HONNETH, 2003. 
La doble contingencia implica que ego cuenta con la posibilidad de que la acción de alter sea diversa de aquella que él proyectó y viceversa. No obstante, no pueda persistir en una «doble contingencia pura» - ya que hay condicionamientos de interacción y la «absorción de inseguridad» ${ }^{84}$ mediante la «estabilización de expectativas» ${ }^{85}$, «la tentativa de prever precisamente lo otro, fracasaría inevitablemente» ${ }^{86}$. Esto importa la suposición mutua de «grados de libertad» ${ }^{87}$ (la acción de alter puede ser muy distinta de la proyectada en el vivenciar de ego y viceversa), que convierte el comportamiento en acción: «El comportamiento se vuelve acción en el espacio de libertad de otras posibilidades de determinación» ${ }^{88}$. Y la propia doble contingencia como «autocatalisadora» de los sistemas sociales ${ }^{89}$ supone la libertad reciproca en la forma de «una incerteza que se condiciona a sí misma» en un circulo autorreferencial: «Yo no me dejo determinar por ti, si tú no te dejas determinar por mí» ${ }^{90}$. De esto se origina, que la doble contingencia en la interacción envuelva una combinación de no-identidad e identidad: «Ego vivencia alter como alter ego. Al mismo tiempo que tiene la experiencia con la no-identidad de las perspectivas, ego vivencia la identidad de esa experiencia de ambos lados» ${ }^{91}$. El problema (de la negación) del reconocimiento en la interacción se produce precisamente cuando uno de los dos polos, en la relación de observación recíproca entre ego y alter, no está dispuesto a soportar la «libertad» del otro, tanto porque no considera su comportamiento como acción (porque no puede ser diferente del comportamiento proyectado por ego), como porque no toma en serio la no-identidad de su perspectiva.

Esbozada de esta forma, la negación del reconocimiento puede ser comprendida como un mal entendido que obstaculiza la emergencia de la doble contingencia como autocatalizadora de los sistemas sociales: «El otro ni siquiera me vio o consideró como posible par en la interacción» ${ }^{92}$. Ese mal entendido, que representa un caso límite, conlleva otra formulación, en la cual se presenta el problema de la negación del reconocimiento: el otro no tolera verme como un par digno de interacciones ${ }^{93}$. La «posibilidad de que también sea de otra manera» ${ }^{94}$ de mi comportamiento (mi acción) no forma parte de su vivenciar, mi perspectiva es despreciada. En tal sentido, el reconocimiento o no-reconocimiento, un problema que surge primariamente en el ámbito de la interacción como sistema social entre presentes, se relaciona con la moral como forma especial de comunicación que se reproduce conforme al código diferencia entre consideración o estima, y desconsideración o desprecio por alguna persona ${ }^{95}$.

84 Cfr. LUHMANN, 1987a (1984): 168 y 185 y ss.

85 LuHMANN, 1987a (1984): 158.

86 «Der Versuch, den anderen zu berechnen, würde zwangsläufig scheitern» [LUHMANN, 1987a (1984): 156].

87 LUHMANN, 1987a (1984): 186.

88 LUHMANN, 1987a (1984): 169.

89 LUHMANN, 1987a (1984): 170 y ss.

90 LUHMANN, 1987a (1984):, 167.

91 LUHMANN, 1987a (1984): 172.

92 Luhmann, 1987a (1984): 166.

93 A partir de otros presupuestos, HonNETH (2003: 12), de manera sugestiva, distingue gradualmente entre la «desatención inofensiva de aquel que olvida saludar a un conocido en una fiesta» y la «invisibilidad» originada en el desprecio, sea «que un ensimismado dueño de casa ignore a su empleada, a quien él no ve por causa de su insignificancia social», o de forma más radical, mediante el «una mirada punzante, que sólo puede ser comprendido como señal de humillación, por parte del negro que es alcanzado por ella».

94 LuHManN, 1987a (1984): 184.

95 Luhmann, 1987a (1984): 319 y ss.; 1989: 361 y ss.; 1990b; 1993b; 1997: 244 y ss. y 396 y ss. 
El peligro de la moralización es que ella se sitúa, en el lado negativo del código binario, en el umbral de la supresión de la persona (el otro) como «dirección del proceso de comunicación» ${ }^{96} \mathrm{y}$, en el caso extremo, de la eliminación del hombre como su substrato corpóreo-psiquico ${ }^{97}$. Adicionalmente, si consideramos la diferencia entre la llamada «interacción» referente a animales no humanos, que no implican substrato de sistemas constituyentes de sentido (son sistemas biológicos), y la interacción como sistema social entre personas presentes ${ }^{98}$, cabe decir que la negación del reconocimiento es un problema de doble contingencia, dado que tiende a retirar del comportamiento del otro, el carácter selectivo de una acción contingente, sin considerar el vivenciar y también las expectativas del otro como orientadoras de los comportamientos de éste: la negación del reconocimiento, tendiendo, de forma extrema, a la «animalización» del otro como cuerpo que se implica, otro indigno de acción y, por tanto, de interacción. Así como LuHMANN afirma respecto a la exclusión de los sistemas sociales (que perciben a los hombres sólo como cuerpos) ${ }^{99}$, es necesario hacer presente lo siguiente cuando hablamos de falta de reconocimiento en la interacción: ego no observa a alter como persona, sino apenas como cuerpo. Finalmente, si consideramos que «una de las consecuencias más importantes de la doble contingencia es el surgimiento de la confianza o desconfianza» ${ }^{100}$, se puede afirmar que en la negación del reconocimiento del otro, la desconfianza se expande de tal forma que impide la construcción de una interacción fundada en la doble contingencia.

No obstante, el problema del reconocimiento del otro en la interacción, como problema de doble contingencia, sea realmente relevante, no tiene en cuanto presupuesto de la esfera pública, la misma importancia que la inclusión ${ }^{101}$. Entre inclusión y reconocimiento existe una asimetría. Puede darse, que en interacciones concretas haya inclusión sin reconocimiento. Todos alguna vez pasamos, en menor o mayor medida, por situaciones de falta de reconocimiento en la interacción o para la interacción en lo cotidiano, incluso perteneciendo al sector de inclusión. Por el contrario, el reconocimiento sin inclusión es imposible. En una cadena de exclusión, en la cual no tener empleo significa también no tener dinero, educación, derechos, acceso al sistema de salud, etc., no es posible hablar de reconocimiento de la respectiva persona en la interacción, sino en un sentido pseudo-asistencialista o pseudocaritativo, de «compasión» con los sufrimientos del cuerpo y del «alma».

En principio, nadie puede exigir reconocimiento en la interacción o para la interacción, a no ser que se trate de una exigencia de la organización (colegas de trabajo en una reunión) o de una conexión funcional (por ejemplo, derecho a ser oído en el proceso); o en los casos extremos de prohibir una moralización negativa que pretende

96 LUHMANN, 1989: 367, nota 11.

97 Cfr. Luhmann, 1989: 368; 1990b: 26.

98 Aquí cabe recordar a MEAD, 1962 (1934): 108, al hacer la distinción entre un hombre y un perro, por la capacidad que el hombre tiene de autocondicionar su comportamiento (acción), mientras el comportamiento del perro sólo puede ser condicionado por un otro.

99 Vid. supra 20.

100 LUHMANN, 1987a (1984): 179.

101 La relación entre inclusión y reconocimiento, aquí analizada, no se confunde con la relación entre distribución y reconocimiento, muy difundida en la discusión filosófico-social dominante (al respecto, vid. Fraser/Honneth, 2003). 
eliminar a la persona del otro (o que en principio, ya constituye en sí misma una cuestión jurídica de derechos personalísimos). Si en una fiesta, nadie entra en interacción conmigo (nadie me ve, «¿por qué no me miras?»), sea cual sea el motivo, esa situación, inicialmente, no podrá ser considerada como negación de un derecho o una pretensión política, ni como una negación y restricción a la construcción de una esfera pública. Inclusive, si en un comicio político, los presentes no prestan la más mínima atención a las palabras de un candidato, esto no puede, en principio, ser tratado como negación de un derecho político o de un presupuesto de la esfera pública. Contraproducentemente, llevaría a una excesiva juridización de la sociedad o a una politización totalitaria de la esfera pública.

Sin embargo, si el problema de la negación del reconocimiento de determinados grupos y personas traspasa los límites de la interacción concreta, tendiendo a la generalización en el mundo de la vida y en la esfera pública, resultan perjudicadas la construcción y el desarrollo de ésta. En tal caso, es preciso observar que el problema de reconocimiento tiende a transformarse en exclusión social de ciertos grupos. Es decir, la generalización de la falta de reconocimiento de ciertas personas en las interacciones del mundo de la vida, engendra su exclusión de los sistemas funcionales (por ejemplo, discriminación de los judíos en la Alemania nazi, y los diversos actos racistas contra negros o grupos étnicos, especialmente en forma de apartheid). Por tanto, pese a su asimetría, la relación entre inclusión y reconocimiento se caracteriza por una circularidad: sin inclusión de las personas en los sistemas funcionales, y por extensión, en la sociedad, no podemos hablar de reconocimiento de las mismas en la interacción, esto es, la exclusión implica la negación del reconocimiento; la generalización del noreconocimiento de personas y grupos en las interacción o hacia las interacciones del mundo de la vida, trae con ella la exclusión de los sistemas funcionales, e impide la construcción y desarrollo de una esfera pública «universalista», indispensable para la concretización y realización de la Constitución del Estado democrático de derecho.

5.

En el ámbito de la estructura de la sociedad mundial del presente, cuya autocomprensión se expresa cada vez más intensamente en la semántica de la globalización, diversos factores contribuyen a la limitación de la esfera pública como poseedora de un complejo entramado, cuyos flujos de sentido sirven a la heterolegitimación de los procedimientos constitucionales del Estado democrático de derecho. En este contexto, también se sugiere la superación del concepto de esfera pública política en virtud del fin de las condiciones de su existencia. En las líneas que siguen, trataré esto en dos niveles: en el primero, los problemas que la esfera pública enfrenta actualmente en el ámbito del Estado constitucional, frente al que se construyó y desarrolló en la sociedad moderna; en el segundo, los límites a las posibilidades de una esfera pública en el plano supra-estatal, transestatal o global.

En el correr de la denominada «globalización económica», con la consecuente expansión del sistema económico en detrimento de la autonomía constitucionalmente fundada de los sistemas jurídico y político. La esfera pública se vio fragilizada debido a su incapacidad de manifestarse de forma relevante sobre temas significativos para 
la reproducción de la sociedad global. La tendencia excluyente del «imperialismo» del código económico, actúa de tal forma, que constituye un factor que traslada las decisiones político-económicas y jurídico-económicas a esferas supra-estatales, transestatales o globales, debilitando tanto el Estado constitucional como la respectiva esfera pública.

Por otra parte, cabe considerar que, en el plano local, es posible observar que la intolerancia étnica ha aumentado y los fundamentalismos se han vuelto más fuertes, resistiendo a la complejidad sistémica y al reconocimiento del otro en la sociedad mundial de la actualidad, negando, de esta manera, el disenso estructural y la heterogeneidad de la esfera pública. Relacionado a esto, se encuentra el problema de la apatía pública. Esto es, la postura de indiferencia a los procedimientos constitucionales. La combinación de los extremismos políticos que tienen su origen en la intolerancia étnica, y los fundamentalismos, con la apatía señalada, tiende a anestesiar la esfera pública construida en torno a los procedimientos jurídicos y políticos del Estado constitucional ${ }^{102}$.

El problema se acrecienta al considerar que los fundamentalismos, traspasando los límites territoriales del Estado, emergen en el plano global en forma de terrorismo étnico y religioso, opuesto a la idea de una esfera pública pluralista. El terrorismo global, se asocia a su vez, con «el imperialismo de los derechos humanos» ${ }^{103}$, política intervencionista, que al invocarlos retóricamente conforme a una lectura Occidental (o más precisamente, norteamericana), pretende destinarse a imponerlos unilateralmente contra los países que supuestamente los ofenden. De tal forma, se ve perjudicada, en ambos lados del conflicto, la posibilidad de construcción, mantenimiento o desarrollo de la esfera pública.

Dichos problemas, se enlazan a los intentos de desarrollo de una esfera pública supra-estatal, transestatal o global ${ }^{104}$. En el plano de la integración regional, sobre todo en el caso de la Unión Europea, la construcción de una esfera pública en torno a los procesos «supranacionales» parece indisociable de la emergencia de una organización política susceptible de ser caracterizada como un equivalente funcional de un Estado constitucional, con los procedimientos en torno a los cuales se articule de forma relevante el entramado de comunicaciones constitutivas de esa nueva esfera pública. Sin su relevancia para los procedimientos jurídicos y políticos, con el llamado «déficit democrático», la esfera pública se caracteriza por su fragilidad. La «esfera pública frágil» actúa muy puntual e intermitentemente, es decir, no es capaz de influenciar de forma generalizada y permanente, los respectivos procedimientos políticos y jurídicos supranacionales, transestatales o globales ${ }^{105}$. Las decisiones tomadas y las normas establecidas por medio de esos procedimientos son, en general, insensibles a las esferas públicas frágiles y marginales en el plano supra-estatal, transestatal o global. En este ámbito, la

102 Cfr. Neves, 2006 (2000): 215-226.

103 NeVES, 2005: 186.

104 Según STICHWEH, 2002: 57: «Esfera pública y esfera pública mundial son fenómenos más o menos simultáneos respecto de su surgimiento». El problema reside, no obstante, en los diferentes niveles de influencia y fuerza legitimadora de la esfera pública relacionada al Estado y de la esfera pública mundial para los respectivos procedimientos políticos y jurídicos.

${ }_{105}$ Cfr. BRUNKHORST, 2002: 184 y ss.; 2007: 233 y ss. En la distinción entre esfera pública «fuerte» y «frágil», BRUNKHORST recurre a FRASER, 1992: 132 y ss. 
inexistencia de una «esfera pública fuerte» dificulta u obstaculiza la heterolegitimación de los respectivos procedimientos.

Frente a estos obstáculos, tanto en el plano estatal como global, se tiende a despreciar el concepto de esfera pública política y jurídica, enfatizando, por otra parte, el concepto de redes. No obstante, la propia esfera pública fuerte es una amalgama compleja de redes emergentes de los sistemas funcionales, y del respectivo mundo de la vida. La sobrevivencia de esa conexión desestructurada de redes es punto central para la legitimación de los procedimientos constitucionales, y consecuentemente, del derecho y de la política de la sociedad mundial, en cuanto sistemas funcionales segmentados territorialmente en Estados. Ante la ausencia de una esfera pública fuerte en el plano global, transestatal o supra-estatal, cabe su rearticulación mediante nuevas redes movilizadas en torno a los procedimientos constitucionales, que, al mismo tiempo, estén abiertas a los procedimientos jurídicos y políticos desarrollados en aquel plano, emergiendo del nivel local al ámbito global. Sin una renovación amplia de la esfera pública constitucional frente a los nuevos problemas de la sociedad mundial heterárquica, el modelo de Estado democrático de derecho, fundado en la Constitución como acoplamiento estructural entre política y derecho, en cuanto sistemas diferenciados segmentariamente en territorios delimitados, o cualquier equivalente funcional en el plano supra-estatal, transestatal o global, se vuelve insustentable.

(Traducción de Nathaly Mancilla Órdenes)

\section{BIBLIOGRAFÍA}

Arendt, H., 1989: The Human Condition, Chicago/London: The University of Chicago Press (1. ${ }^{a}$ ed., 1958).

BENDIX, R., 1969: Nation-Building and Citizenship. Studies of our changing social order, Garden City, New York: Anchor (1. ${ }^{a}$ ed., 1964).

Blumenberg, H., 1998: Paradigmen zu einer Methaphorologie, Frankfurt am Main: Suhrkamp.

BORA, A., 2002: «"Wer gehört dazu?” Überlegungen zur Theorie der Inklusion», en K.-U. Hellmann y R. Schmalz-Bruns (orgs.), Theorie der Politik: Niklas Lubmanns politische Soziologie, Frankfurt am Main: Suhrkamp, 60-84.

BRUnKHORST, H., 2002: Solidarität: Von der Bürgerfreundschaft zur globalen Rechtsgenossenschaft, Frankfurt am Main: Suhrkamp.

- 2007: «Zwischen transnationaler Klassenherrschaft und egalitärer Konstitutionalisierung. Europas zweite Chance», en P. NIESEN y B. HERBORTH (orgs.), Anarchie der kommunikativen Freiheit: Jürgen Habermas und die Theorie der internationalen der Politik, Frankfurt am Main: Suhrkamp, 321-349.

EngELS, F., 1988: «Die Lage Englands. II. Die englische Konstitution», en K. MarX y F. EngELS, Werke, 15. ed., Berlin: Dietz Verlag, vol. I, $569-592$ (originalmente in: Vorwärts!, núm. 75, de 18 de septiembre de 1844).

Fraser, N., 1992: «Rethinking the Public Sphere: A Contribution to the Critique of Actually Existing Democracy», en C. CALHOun (org.), Habermas and Public Sphere, Cambridge/MA: The MIT Press, 109-142.

- 2004: «Institutionalizing Democratic Justice: Redistribution, Recognition, and Participation», en S. BENHABIB y N. FrASER (orgs.), Pragmatism, Critique, Judgment: Essays for Richard J. Bernstein, Cambridge/MA: The MIT Press, 125-147. 
FraSER, N., y HonNETH, A., 2003: Umverteilung oder Anerkennung? Eine politisch-philosophische Kontroverse, Frankfurt am Main: Suhrkamp.

Fischer-Lescano, A., y TeubneR, G., 2006: Regime-Kollisionen: Zur Fragmentierung des globalen Rechts, Frankfurt am Main: Suhrkamp.

GRIMM, D., 1987: «Entstehungs- und Wirkungsbedingungen des modernen Konstitutionalismus», en Akten des 26. Deutschen Rechtshistorikertages, Frankfurt am Main, 22. bis 26. September 1986, Org. Dieter Simon, Frankfurt am Main: Klostermann, 45-76.

- 1989: «Verfassung», Staatslexikon: Recht - Wirtschaft - Gesellschaft, Org. Görres-Gesell-

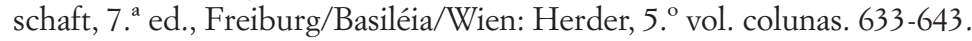

— 1995: «Konstitution, Grundgesetz(e) von der Aufklärung bis zur Gegenwart», MoHNHAUPT y GRIMM, 1995, 100-141.

Habermas, J., 1978: Theorie und Praxis, Frankfurt am Main: Suhrkamp.

- 1982: Theorie des kommunikativen Handelns, 2. ${ }^{a}$ ed., Frankfurt am Main: Suhrkamp, 2 vols.

- 1983: Moralbewußtsein und kommunikatives Handeln, Frankfurt am Main: Suhrkamp (trad. bras.: Consciência Moral e Agir Comunicativo, Rio de Janeiro: Tempo Brasileiro, 1989).

- 1986: Vorstudien und Ergänzungen zur Theorie des kommunikativen Handelns, Frankfurt am Main: Suhrkamp.

- 1990: Strukturwandel der Öffentlichkeit: Untersuchungen zu einer Kategorie der bürgerlichen Gesellschaft, Frankfurt am Main: Suhrkamp (1. ${ }^{a}$ ed., Neuwied: Luchterhand, 1962).

- 1991: Erläuterung zur Diskursethik, Frankfurt am Main: Suhrkamp.

- 1992: Faktizität und Geltung: Beiträge zur Diskurstheorie des Rechts und des demokratischen Rechtsstaats, Frankfurt am Main: Suhrkamp.

- 1999: Wabrbeit und Rechtfertigung: Philosophische Aufsätze, Frankfurt am Main: Suhrkamp.

Hegel, G. W. F., 1967: Jenaer Realphilosophie: Vorlesungsmanuskripte zur Philosophie der Natur und des Geistes von 1805-1806, Org. Johannes Hoffmeister, Hamburg: Meiner (reimpressão inalterada da $1^{\text {a }}$ edição, de 1931, sob o título Jenenser Realphilosophie II).

- 1988: Phänomenologie des Geistes, Hamburgo: Meiner (1. 'a ed., Bamberg/Würzburg, 1807).

Honneth, A., 1994: Kampf um Anerkennung: Zur moralischen Grammatik sozialer Konflikte, Frankfurt am Main: Suhrkamp.

- 2003: Unsichtbarkeit: Stationen einer Theorie der Intersubjektivität, Frankfurt am Main: Suhrkamp.

Heller, H., 1934: Staatslebre, Org. Gerhart Niemeyer, Leiden: Sijthoff (trad. bras.: Teoria do Estado, São Paulo: Mestre Jou, 1968).

Holz, K., 2000: «Citizenship. Mitgliedschaft in der Gesellschaft oder differenzierungstheoretisches Konzept?», en K. Holz (org.), Staatsbürgerschaft: Soziale Differenzierung und politische Inklusion, Opladen: Westdeutscher Verlag, 187-208.

Kelsen, H., 1925: Allgemeine Staatslebre, Berlin: Verlag von Julius Springer.

- 1946: General Theory of Law and State, trad. ingl. A. WEDBERG, Cambridge-Massachusetts: Harvard University Press (trad. bras.: Teoria geral do direito e do estado, 3. . ed., 2. ${ }^{a}$ tiragem, São Paulo: Martins Fontes, 2000).

- 1960: Reine Rechtslebre, 2. ${ }^{a}$ ed., Wien: Franz Deuticke (reimpressão inalterada: 1983) (trad. bras.: Teoria pura do direito, 6. ${ }^{a}$ ed., 5. ${ }^{a}$ tiragem, São Paulo: Martins Fontes, 2003).

Laclau, E., 1994: «Why do Empty Signifiers Matter to Politics?», en J. WeEKS (org.), The Lesser Evil and the Greater Good. The Theory and Politics of Social Diversity, London: Rivers Oram Press, 167-178.

LASSALlE, F., 1987: «Über Verfassungswesen» (1962), en Reden und Schriften, Org. Hans Jürgen Friederici, Colônia: Röderberg, 120-147 (trad. bras.: Que é uma Constituição?, Porto Alegre: Editorial Villa Martha, 1980). 
LEFORT, C., 1981: «Droit de l'homme et politique», en C. LEFORT, L'Invention Démocratique: Les limites de la domination totalitaire, Paris: Fayard, 45-83 (trad. bras.: «Direitos do homem e política», en $A$ Invenção democrática: Os limites do totalitarismo, 2. ${ }^{a}$ ed., São Paulo: Brasiliense, 1987, 37-69).

LÉvi-STRAuss, C., 1973: «Introduction à l'œuvre de Marcel Mauss», en M. Mauss, Sociologie

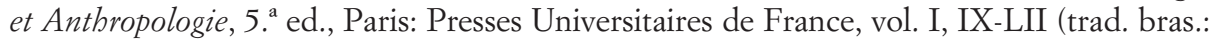
«Introdução à Obra de Marcel Mauss», en M. MAuss, Sociologia e Antropologia, São Paulo: EPU/EDUSP, 1974, vol. I, 1-36).

LuHMANN, N., 1965: Grundrechte als Institution: Ein Beitrag zur politischen Soziologie, Berlin: Duncker \& Humblot.

- 1975: «Interaktion, Organisation, Gesellschaft», en N. LuHmanN, Soziologische Aufklärung 2: Aufsätze zur Theorie der Gesellschaft, Opladen: Westdeutscher Verlag, 9-20.

- 1980: «Gesellschaftliche Struktur und semantische Tradition», en N. LuHManN, Gesellschaftsstruktur und Semantik: Studien zur Wissenssoziologie der modernen Gesellschaft, Frankfurt am Main: Suhrkamp, vol. 1, 9-71.

- 1981a: Politische Theorie im Woblfahrtsstaat, Munique: Olzog.

- 1981b: «Machtkreislauf und Recht in Demokratien», en Zeitschrift für Rechtssoziologie, 2. Opladen: Westdeutscher Verlag, 158-167.

- 1986: «Die Codierung des Rechtssystems», en Rechtstheorie, 17, Berlin: Duncker \& Humblot, 171-203.

- 1987a: Soziale Systeme: Grundriß einer allgemeinen Theorie, Frankfurt am Main: Suhrkamp (1. ${ }^{a}$ tiragem: 1984$)$.

- 1987b: Rechtssoziologie, 3. ${ }^{a}$ ed., Opladen: Westdeutscher Verlag (1. ${ }^{a}$ ed., Reinbek bei Hamburg: Rowohlt, 1972, 2 vols.).

- 1988a: Macht, 2. ${ }^{a}$ ed., Stuttgart: Enke (1. ${ }^{a}$ ed., 1975) (trad. bras.: Poder, 2. ${ }^{a}$ ed., Brasília: UnB, 1992).

- 1988b: Die Wirtschaft der Gesellschaft, Frankfurt am Main: Suhrkamp.

- 1989: Gesellschaftsstruktur und Semantik: Studien zur Wissenssoziologie der modernen Gesellschaft, Frankfurt am Main: Suhrkamp, vol. 3.

- 1990a: «Verfassung als evolutionäre Errungenschaft», en Rechtshistorisches Journal, 9, Frankfurt am Main: Löwenklau, 176-220.

- 1990b: Paradigma lost: Über die ethische Reflexion der Moral-Rede anläßlich der Verleibung des Hegel-Preises 1989, incluida a «Laudatio» de R. SPAEmanN, Frankfurt am Main: Suhrkamp.

- 1990c: Liebe als Passion: Zur Codierung von Intimität, 5. ${ }^{\text {a }}$ ed., Frankfurt am Main: Suhrkamp (1. ${ }^{a}$ ed., 1982).

- 1990d: Die Wissenschaft der Gesellschaft, Frankfurt am Main: Suhrkamp.

— 1992: «Zur Einführung», en NEVES, 1992, 1-4.

- 1993a: Das Recht der Gesellschaft, Frankfurt am Main: Suhrkamp.

- 1993b: «The Code of the Moral», en Cardozo Law Review, vol. 14, núms. 3-4, New York: Cardozo Law School, jan. 1993, 995-1009.

- 1994: «Europa als Problem der Weltgesellschaft», en Berliner Debatte INITIAL: Zeitschrift für sozialwissenschaftlichen Diskurs, 2/1994, Berlin: GSFP, 3-7.

- 1995a: «Inklusion und Exklusion», en N. LuhmanN, Soziologische Aufklärung 6: Die Soziologie und der Mensch, Opladen: Westdeutscher Verlag, 237-264.

- 1995b: Gesellschaftsstruktur und Semantik: Studien zur Wissenssoziologie der modernen Gesellschaft, Frankfurt am Main: Suhrkamp, vol. 4. 
- 1996a: Protest: Systemtheorie und soziale Bewegungen, Org. Kai-Uwe Hellmann, Frankfurt am Main: Suhrkamp.

- 1996b: Die Kunst der Gesellschaft, 2. ${ }^{a}$ ed., Frankfurt am Main: Suhrkamp.

- 1997: Die Gesellschaft der Gesellschaft, Frankfurt am Main: Suhrkamp, 2 tomos.

- 1998: «Der Staat des politischen Systems: Geschichte und Stellung in der Weltgesellschaft», en U. BECK (org.), Perspektiven der Weltgesellschaft, Frankfurt am Main: Suhrkamp, 1998, 345-380.

- 1999: «Ethik in internationalen Beziehungen», en Soziale Welt, 50, Baden-Baden: Nomos, 247-254.

- 2000a: Die Politik der Gesellschaft, Frankfurt am Main: Suhrkamp.

- 2000b: Die Religion der Gesellschaft, Frankfurt am Main: Suhrkamp.

- 2002a: Einführung in die Systemtheorie, Org. Dirk Baecker, Heidelberg: Carl-Auer-Systeme.

- 2002b: Das Erziebungssystem der Gesellschaft, Frankfurt am Main: Suhrkamp.

- 2004: «Codierung und Programmierung: Bildung und Selektion im Erziehungssystem» (1986), en Schriften zur Pädagogik, Org. Dieter Lenzen, Frankfurt am Main: Suhrkamp, 23-47.

MacDowell, D. M., 1989: «The Oikos in Athenian Law», en The Classical Quarterly, New Series, vol. 39, núm. 1, Cambridge: Cambridge University Press, 10-21.

Marshall, T. H., 1976: «Citizenship and Social Class» (1949-1950), en T. H. Marshall, Class, Citizenship and Social Development, Westport, Connecticut: Greenwood Press (reimpressão da edição de Nova York, 1964), 65-122.

MarX, K., 1988: «Zur Judenfrage», en K. MarX y F. Engels, Werke, 15.a ed., Berlin: Dietz Verlag, vol. I, 347-377 (originariamente en: Deutsch-Französische Jabrbücher, Paris, 1944).

MeAD, G. H., 1962: Mind, Self, E Society: from the Standpoint of a Social Behaviorist, Org. e intr. Charles W. Morris. Chicago/Londres: The University of Chicago Press (1. ${ }^{a}$ ed., 1934).

Mohnhaupt, H., 1995: «Konstitution, Status, Leges fundamentales von der Antike bis zur Aufklärung», en MOHNHAUPT y GRIMM, 1995, 1-99.

Mohnhaupt, H., y Grimm, D., 1995: Verfassung: Zur Geschichte des Begriffs von der Antike bis zur Gegenwart; zwei Studien, Berlin: Duncker \& Humblot.

MÖLLERS, Ch., 2005: «Netzwerk als Kategorie des Organisationsrechts —zur juristischen Beschreibung dezentraler Steuerung—》, en J. OEBBECKE (org.), Nicht-normative Steuerung in dezentralen Systemen (Nassauer Gespräche der Freiherr-Vom-Stein-Gesellschaft, vol. 7), Stuttgart: Franz Steiner Verlag, 285-302.

Neves, M., 1992: Verfassung und Positivität des Rechts in der peripheren Moderne: Eine theoretische Betrachtung und eine Interpretation des Falls Brasilien, Berlin: Duncker \& Humblot.

- 1994: «Entre Subintegração e Sobreintegração: A Cidadania Inexistente», en DADOS - Revista de Ciências Sociais, vol. 37, núm. 2, Rio de Janeiro: IUPERJ, 253-276.

— 2005: «Die Symbolische Kraft der Menschenrechte», en Archiv für Recht und Sozialphilosophie, 91/2, Stuttgart: Franz Steiner, 159-187.

- 2006: Entre Têmis e Leviatã: Uma Relação Difícil. O Estado Democrático de Direito a partir e além de Lubmann e Habermas, São Paulo: Martins Fontes (original: Zwischen Themis und Leviathan: Eine Schwierige Beziehung. Eine Rekonstruktion des demokratischen Rechtsstaates in Auseinandersetzung mit Lubmann und Habermas, Baden-Baden: Nomos, 2000).

PARSONS, T., 1968: «Interaction: Social Interaction», en International Encyclopedia of the Social Sciences, vol. 7, New York: The MacMillan Company \& The Free Press/London: Collier Macmillan Publishers, 429-441 (reimpressão, 1972).

- 1971: The System of Modern Societies, Englewood Cliffs, Nova Jersey: Prentice-Hall, 1971 (trad. bras.: O sistema das sociedades modernas, São Paulo: Pioneira, 1974). 
— 1994: «Full Citizenship for the Negro American: A Sociological Problem» (1965), en B. S. Turner y P. Hamilton (orgs.), Citizenship: Critical Concepts, London/New York: Routledge, vol. II, 141-175.

PARSONS, T., et al., 1951: «Some Fundamental Categories of the Theory of Action: A General Statement», en T. Parsons y E. A. SHILs (orgs.), Toward a General Theory of Action, Cambridge, MA: Harvard University Press, 3-29 (6. impressão, 1967).

PETERS, B., 1993: Die Integration moderner Gesellschaften, Frankfurt am Main: Suhrkamp.

SKINNER, Q., 1989: «Language and political change», en T. BALL, J. FARR y R. L. HANSON (orgs.), Political Innovation and conceptual Change, Cambridge: Cambridge University Press, 6-23.

SMEND, R., 1968: «Verfassung und Verfassungsrecht (1928)», en R. SMEND, Staatsrechtliche Abbandlungen und andere Aufsätze, 2. ${ }^{a}$ ed., Berlin: Duncker \& Humblot, 119-276.

STichweH, R., 1997: «Inklusion/Exklusion, funktionale Differenzierung und die Theorie der Weltgesellschaft», en Soziale Systeme: Zeitschrift für soziologische Theorie, 3, Opladen: Leske + Budrich, 123-136.

— 2002: «Die Entstehung einer Weltöffentlichkeit», en H. KAELbLE, M. KirSCH y A. SCHMIDTGERNIG (orgs.), Transnationale Öffentlicbkeiten und Identitäten im 20. Jabrbundert, Frankfurt am Main/Nova York: Campus, 57-66.

STOURZH, G., 1975 o 1989: «Vom aristotelischen zum liberalen Verfassungsbegriff. Zur Entwicklung in Nordamerika im 17. und 18. Jahrhundert», en F. ENGEL-JANOSI, G. KLINGENSTEIN y H. LuTZ (orgs.), Fürst, Bürger, Mensch: Untersuchungen zu politischen und soziokulturellen Wandlungsprozessen im vorrevolutionären Europa, Munique: R. Oldenbourg, 1975, 97-122. Posteriormente, com algumas alterações: «Vom aristotelischen zum liberalen Verfassungsbegriff. Staatsformenlehre und Fundamentalgesetze in England und Nordamerika im 17. und 18. Jahrhundert», en G. STOURZH, Wege zur Grundrechtsdemokratie: Studien zur Begriffs- und Institutionengeschichte des liberalen Verfassungsstaates, Wien/Colônia: Böhlau, 1989, 1-35.

TAYLOR, Ch., 1993: Multikulturalismus und die Politik der Anerkennung, Frankfurt am Main: Fischer.

- 1995: Das Unbehagen an der Moderne, Frankfurt am Main: Suhrkamp.

Teubner, G., 1996: «Altera Pars Audiatur: Das Recht in der Kollision anderer Universalitätsansprüche», en Archiv für Rechts- und Sozialphilosophie, núm. suplementar (Beibeft), 65. Wiesbaden: Steiner, 199-220 (trad. bras.: «Altera pars adiatur: o direito na colisão de discursos», en G. Teubner et al., Direito e cidadania na pós-modernidade, Piracicaba: UNIMEP, 2002, 91-129).

- 1998: «Nach der Privatisierung? Diskurskonflikte im Privatrecht», en Zeitschrift für Rechtssoziologie, 19, Wiesbaden: Westdeutscher Verlag, 8-36 (trad. bras.: «Após a privatização: conflitos de discursos no direito privado», en G. TEUBNER, Direito, sistema e policontexturalidade, Piracicaba: UNIMEP, 2005, 233-68).

THÜRER, D., 1996: «Der Wegfall effektiver Staatsgewalt: “The Failed State”, en Berichte der Deutschen Gesellschaft für Völkerrecht, 34, Heidelberg: C. F. Müller, 9-47.

WeBER, M., 1985: Wirtschaft und Gesellschaft: Grundriß der verstehenden Soziologie, 5. ${ }^{a}$ ed., Org. Johannes Winckelmann, Tübingen: Mohr (1. ${ }^{a}$ ed., 1922) (trad. bras.: Economia e sociedade: fundamentos da sociologia compreensiva, Brasilia: UnB/São Paulo: Imprensa Oficial, 2004, 2 vols.).

WitTGenstein, L., 1997: «Philosophische Untersuchungen»(1945-1949), en L. WitTGeNSTEIN, Werkausgaben, 11. ' ed., Frankfurt am Main: Suhrkamp, vol. 1, $225-580$ (trad. bras.: Investigações Filosóficas, 2. ${ }^{a}$ ed., São Paulo: Abril Cultural, 1979, col. «Os Pensadores»). 